\title{
Impact Modelling and A Posteriori Non-destructive Evaluation of Homogeneous Particleboards of Sugarcane Bagasse
}

\author{
Hai Zhang ${ }^{1} \cdot$ Stefano Sfarra ${ }^{2,3} \cdot$ Fabrizio Sarasini $^{4} \cdot$ Juliano Fiorelli $^{5}$. Jeroen Peeters ${ }^{6} \cdot$ Nicolas P. Avdelidis $^{1,7}$. \\ Diogo de Lucca Sartori ${ }^{8}$. Clemente Ibarra-Castanedo ${ }^{1}$. Stefano Perilli ${ }^{2}$ - Yacine Mokhtari ${ }^{1}$. Jacopo Tirillò ${ }^{4}$. \\ Xavier P. V. Maldague ${ }^{1}$
}

Received: 25 March 2017 / Accepted: 3 January 2018 / Published online: 12 January 2018

(c) Springer Science+Business Media, LLC, part of Springer Nature 2018

\begin{abstract}
With a view to gaining an in-depth assessment of the response of particleboards (PBs) to different in-service loading conditions, samples of high-density homogeneous PBs of sugarcane bagasse and castor oil polyurethane resin were manufactured and subjected to low velocity impacts using an instrumented drop weight impact tower and four different energy levels, namely 5, 10, 20 and 30 J. The prediction of the damage modes was assessed using Comsol Multiphysics ${ }^{\circledR}$. In particular, the random distribution of the fibres and their lengths were reproduced through a robust model. The experimentally obtained dent depths due to the impactor were compared with the ones numerically simulated showing good agreement. The post-impact damage was evaluated by a simultaneous system of image acquisitions coming from two different sensors. In particular, thermograms were recorded during the heating up and cooling down phases, while the specklegrams were gathered one at room temperature (as reference) and the remaining during the cooling down phase. On one hand, the specklegrams were processed via a new software package named Ncorr v.1.2, which is an open-source subset-based 2D digital image correlation (DIC) package that combines modern DIC algorithms proposed in the literature with additional enhancements. On the other hand, the thermographic results linked to a square pulse were compared with those coming from the laser line thermography technique that heats a line-region on the surface of the sample instead of a spot. Surprisingly, both the vibrothermography and the line scanning thermography methods coupled with a robotized system show substantial advantages in the defect detection around the impacted zone.
\end{abstract}

Keywords Numerical simulation · Digital image correlation · Infrared thermography · Profilometry · Sugarcane bagasse Low velocity impact

Stefano Sfarra

stefano.sfarra@univaq.it

1 Computer Vision and Systems Laboratory, Department of Electrical and Computer Engineering, Laval University, Quebec G1V 0A6, Canada

2 Department of Industrial and Information Engineering and Economics (DIIIE), University of L'Aquila, Piazzale E. Pontieri 1, Monteluco di Roio, 67100 L'Aquila, Italy

3 Tomsk Polytechnic University, Lenin Av., 30, Tomsk 634050, Russia

4 Department of Chemical Engineering Materials Environment \& UDR INSTM, Sapienza University of Rome, Via Eudossiana 18, 00184 Rome, Italy

5 Faculty of Animal Science and Food Engineering, University of São Paulo - USP, Av. Duque de Caxias Norte 225, Pirassununga, SP CEP 13635-900, Brazil

\author{
Abbreviations \\ ABNT Associacao Brasileira de Normas Tecnicas \\ ANSI American National Standards Institute \\ BD Bulk density \\ CIS Cold image subtraction \\ CMOS Complementary metal-oxide-semiconductor \\ $\mathrm{CV} \quad$ Coefficient of variation \\ DIC Digital image correlation
}

6 Op3Mech Research Group, Department of Electromechanics, Faculty of Applied Engineering, University of Antwerp, CGB - Z324 Groenenborgerlaan 171, 2020 Antwerp, Belgium

7 Aerospace Integration Research Centre (AIRC), College Road, Cranfield MK43 OAL, UK

8 School of Science and Engineering, São Paulo State University (UNESP), Tupã, SP, Brazil 


$\begin{array}{ll}\text { EOF } & \text { Empirical orthogonal function } \\ \text { FEM } & \text { Finite element method } \\ \text { FOV } & \text { Field of view } \\ \text { FPAs } & \text { Focal plane arrays } \\ \text { FT } & \text { Flash thermography } \\ \text { GUI } & \text { Graphical user interface } \\ \text { HD } & \text { Hardness } \\ \text { IRT } & \text { Infrared thermography } \\ \text { LLT } & \text { Laser line thermography } \\ \text { LSgT } & \text { Line scanning thermography } \\ \text { LStT } & \text { Laser spot thermography } \\ \text { MDFs } & \text { Medium-density fiberboards } \\ \text { MDI } & \text { Methylenediphenyl isocyanate } \\ \text { MOE } & \text { Modulus of elasticity } \\ \text { MOR } & \text { Modulus of rupture } \\ \text { Nd:YAG } & \text { Neodymium-doped yttrium-aluminium-garnet } \\ \text { NDT } & \text { Non-destructive testing } \\ \text { NETD } & \text { Noise equivalent temperature difference } \\ \text { PBs } & \text { Particleboards } \\ \text { PCT } & \text { Principal component thermography } \\ \text { PDE } & \text { Partial differential equation } \\ \text { PT } & \text { Pulsed thermography } \\ \text { ROI } & \text { Region of interest } \\ \text { SCB } & \text { Sugarcane bagasse } \\ \text { SH } & \text { Screw-holding } \\ \text { SPT } & \text { Square pulse thermography } \\ t_{\text {obs }} & \text { Time of observation } \\ \text { THz } & \text { Terahertz } \\ \text { TS } & \text { Thickness swelling } \\ \text { VT } & \text { Vibrothermography } \\ \text { WA } & \text { Water absorption } \\ & \end{array}$

\section{Introduction}

In order to face the ever increasing demand for energy efficient building materials, there is the need to develop cost effective and environmentally friendly technologies and materials. In this regard, particleboards (PBs) and mediumdensity fiberboards (MDFs), which are practical and cheap alternatives to solid wood, have become leading building materials in the past decade [1].

In particular, a PB is a panel product made of sawdust and wood shavings bonded together by synthetic resin and pressed into sheets. Used primarily as core material for doors, furniture, and cabinets, a PB is often covered on one or both sides with veneer or another surface finish. Though easy to produce and well-suited for a host of uses, the use of PBs has raised two different and serious concerns.

The first one is related to the availability of wood residues that is not keeping pace with the increasing demand whilst the second one is due to the fact that currently most PBs use formaldehyde-based resins, which are responsible for formaldehyde gas emissions from factories, into the workplace and into the home. Formaldehyde is regarded as human carcinogen and remains a health concern even at low levels.

These two problems can be effectively faced when considering that there is the opportunity to use post-consumer waste wood and waste paper and agricultural residues as raw materials and more benign resins [2].

Aside from any economic advantage, these alternatives also offer environmental benefits such as diversion of waste from landfills or burning. It is not surprising that many studies have been undertaken to develop PBs with lower environmental impact. In many cases these involved replacing the wood particles with renewable biomass (agro-fibers) and many alternatives have been proposed: pine cones [3], hazelnut, macadamia, almond and peanut shell [4-8], sunflower stalks [9], eggplant stalks [10], banana bunch [11], maize husk [12], coconut husk (coir) [13], kenaf [14], cement bag [15].

Among the agricultural residues, bagasse is one of the largest non-wood lignocellulose by-products that is left over after the crushing and extraction of the juice from the sugarcane (Saccharum officinarum L.) [16]. While this by-product is partly reused as a fuel for the sugar factories themselves [17], large quantities of this waste are still left unused or burnt.

Over the last decades other potential alternative uses have been investigated for this by-product [18], for instance as fiber in polymer-matrix composites [19,20], or in more environmentally friendly PBs [21,22].

In most cases, formaldehyde resins have been used as adhesive, although the most widely used alternative to urea formaldehyde is methylenediphenyl isocyanate (MDI), which does not emit a toxic gas during use. MDI has other advantages, including the ability to bond to wood particles with higher moisture content while requiring less drying energy and lower press temperatures, but still there are concerns about MDI toxicity for workers exposed during PBs and MDF manufacturing. These health concerns have prompted researchers to develop naturally derived adhesives and resins for wood products, such as resins manufactured from furfuryl alcohol, lignin chemicals or castor oil polyurethane adhesive which already exhibited promising results [23].

Similarly to what happens with conventional composite laminates and sandwich structures, the strength properties in the transverse direction of PBs are limited and therefore they show poor impact resistance. Though impact resistance may be an important property for these panel applications, very limited attention has been devoted to this property in literature [24].

In this framework, the aim of the present study was to develop and assess the mechanical properties in both quasi- 
static and dynamic conditions (low velocity impact) of a PB made from sugarcane bagasse (SCB) and a bio-resin derived from castor oil. None of the research works on PBs investigated the modelling of the impact $[25,26]$, nor the evaluation of satellite defects [27] caused by the impact itself via thermographic [28,29] and speckle analyses [30]. However, it has been proven that a combination of the above-mentioned techniques is very useful for the evaluation of the post-impact damage [31-33].

The present work makes a significant progress in the research field of the mechanical impact, since it addresses the prediction of the damage in homogeneous PBs of SCB by using numerical simulations carried out using the Comsol Multiphysics ${ }^{\circledR} 5.0$ software [34] along with the application of a very recent software, named Ncorr v.1.2 [35], which is able to analyse speckle patterns via a digital image correlation (DIC) technique [36]. In addition, the use of the laser spot and laser line thermography (LStT-LLT) methods [37,38], combined with the well-known flash and square pulse thermography (FT-SPT) methods [39,40], revealed unsuspected defects via image processing around the point of impacts.

Similar results were obtained after the application of the vibrothermography (VT) [41] and line scanning thermography (LSgT) [42] methods. In particular, the first method works very well in spite of the large attenuation coefficient of SCB, while the second method was at first combined with a recent pseudo-static algorithm [43] in order to analyse all images simultaneously, thereby reducing the computational cost, and subsequently by applying the principal component thermography (PCT) [44] or cold image subtracted (CIS) technique to improve the defect signature. However, the PCT algorithm was used in the four cases analysed for consistency purposes.

Thin and thick samples were analysed, although in this work only the thin ones will be considered, while in a future work the thermographic simulations and a discussion on the heat conduction through the material will be added [44-47].

The main results are shown, discussed and compared with each other, case by case.

(a)

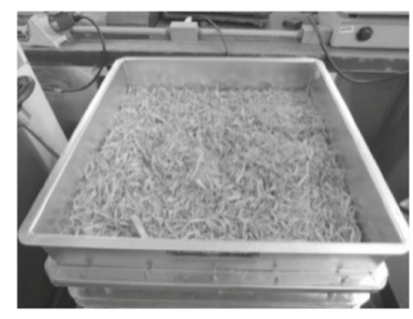

(b)

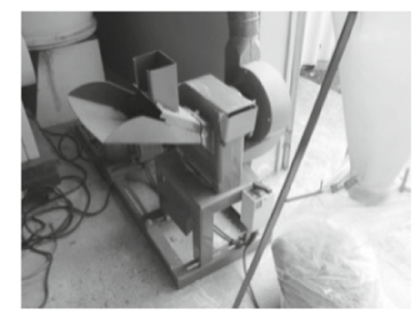

2 Fabrication and Preliminary Mechanical Characterization of Particleboards

The production process of the high-density homogeneous PBs [48] of SCB and polyurethane resin based on castor oil followed the methodology outlined in [49], assuming a nominal density of $800 \mathrm{~kg} / \mathrm{m}^{3}$ and dimensions of $0.55 \times 0.55 \times$ $0.016 \mathrm{~m}$. Initially, the SCB was oven dried at a temperature of $60^{\circ} \mathrm{C}$ for $24 \mathrm{~h}$ to reduce the moisture content to around $12 \%$. After drying, it was sieved in a sieve shaker (Fig. 1a). The bagasse particles retained in the sieve mesh with openings greater than $2 \mathrm{~mm}$ were milled in a knife mill to produce particles of size up to $8 \mathrm{~mm}$ (Fig. 1b). The particles with a size lower than $2 \mathrm{~mm}$ were removed from the manufacturing process because they are not suitable for the step of dispersing the resin.

Subsequently, the particles of SCB were introduced in a planetary mixer and the polyurethane resin based on castor oil was added, in a proportion of $15 \%$ by weight of the dry mass of bagasse, for better uniformity in the distribution of the adhesive in particles. After this mixing period, the particles were introduced into a mattress forming mold, with dimensions of $0.55 \times 0.55 \mathrm{~m}$ and pressed with a pressure of $5 \mathrm{MPa}$ at a temperature of $100{ }^{\circ} \mathrm{C}$, for a period of $10 \mathrm{~min}$ (Fig. 1c). At the end of the pressing process, the complete curing process of the resin required a period of $72 \mathrm{~h}$. The physical (Table 1a) and mechanical properties (Table 1b) of high-density homogeneous PBs (Fig. 1d) were evaluated in accordance with the Brazilian standard [50], and also compared with the American standard [48]. The use of these standards is justified by the similarity of the product developed in this study with wood PBs. The properties evaluated were bulk density (BD), thickness swelling (TS), water absorption (WA), modulus of rupture (MOR), modulus of elasticity (MOE), hardness (HD) and screw-holding (SH). Although the importance of these properties can be found elsewhere [23], Table 1 summarizes the physical and mechanical properties of the PBs investigated in the present study to provide the reader with a complete set of data potentially useful to establish a comparison with standard PBs.

(c)

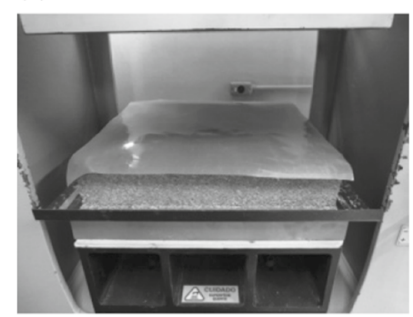

(d)

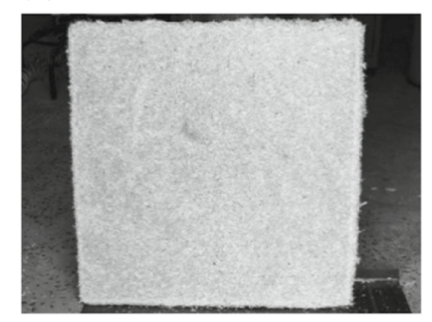

Fig. 1 a Sieve shaker, $\mathbf{b}$ knife mill, $\mathbf{c}$ mattress particles in the hydraulic press with heating, and $\mathbf{d}$ high-density homogeneous particleboards of SCB and the polyurethane resin based on castor oil 
Table 1 (a) Physical properties of PBs, and (b) mechanical properties of particleboards $(\mathrm{CV}$ is the coefficient of variation, ANSI stands for American National Standards Institute, ABNT stands for Associacao Brasileira de Normas Tecnicas, while NBR is the Brazilian standard identifier name)

\section{Properties}

Experimental mean $(\mathrm{CV}, \%)$

ABNT NBR 14.810

ANSI A208.1

(a)

$\begin{array}{ll}\text { BD }\left(\mathrm{kg} / \mathrm{m}^{3}\right) & 742(7) \\ \text { TS } 2 \mathrm{~h}(\%) & 7(21) \\ \text { TS } 24 \mathrm{~h}(\%) & 18(14) \\ \text { WA 2h (\%) } & 13(19) \\ \text { WA 24h (\%) } & 43(18)\end{array}$

(b)

$\begin{array}{ll}\text { MOR (MPa) } & 25.68(11) \\ \text { MOE (MPa) } & 2265(6) \\ \text { HD (N) } & 5000(22) \\ \text { SH face (N) } & 1978(12) \\ \text { SH edge (N) } & 742(29)\end{array}$

$\begin{array}{ll}551-750 & 800 \\ 8 & - \\ - & 8 \\ - & - \\ - & - \\ - & \\ 18 & 16.5 \\ - & 2400 \\ - & 2225 \\ - & 1800 \\ - & 1325\end{array}$

\section{Low Velocity Impact Tests and Profilometry}

Low velocity impact tests at four different energy levels, namely 5, 10, 20 and $30 \mathrm{~J}$ were carried out using an instrumented drop-weight impact testing machine (CEAST/Instron 9340). Both thick and thin samples were impacted, although only the thin samples will be analysed in the following by non-destructive testing (NDT) techniques. However, in this section a comparison among them is also discussed, in order to provide the readers with a clear vision concerning the mechanical responses in relation to the $z$ dimension.

During all impact tests, a steel mass was attached to the steel impactor with a hemispherical tup of $20 \mathrm{~mm}$ diameter for a total weight of $3 \mathrm{~kg}$. The different energy levels were obtained by changing the height of release of the impactor. The specimens were clamped circumferentially along a diameter of $40 \mathrm{~mm}$ in a pneumatic-actuated clamping fixture. During the test, the time history of impact force and the initial impact velocity were recorded.

After the impact event, the permanent dent depth of each coupon was measured using a non-contact profilometer (Taylor-Hobson Talyscan 150) with a scanning speed of $10,500 \mu \mathrm{m} / \mathrm{s}$. The large variability between the dent depth as a function of impact energy for the thin $(16 \mathrm{~mm})$ and thick (20 mm) samples (Fig. 2) has induced the authors to also analyse the thick samples. The results obtained will be reported in a future manuscript.

The materials investigated in the present work exhibited the typical case of free fall, stop and rebound during drop weight impact tests at least in the range 5-30 J. The force versus displacement curves (Fig. 3b) show a closed loop while the area inside the loop refers to the energy absorbed during the impact which was found to grow until the maximum displacement is reached (the maximum energy level is equal to the initial kinetic energy of the impactor) then

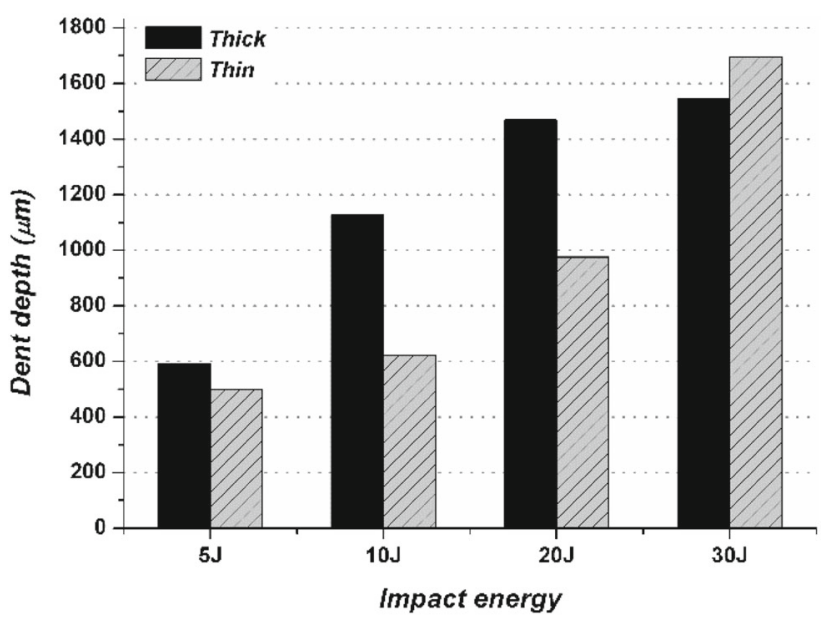

Fig. 2 Dent depth as a function of impact energy for thick and thin samples

it decreases until the dart detaches from the plate (Fig. 3c). The contact force history curves (Fig. 3a) are very similar and symmetrical, without evidence of load drops which are usually ascribed to damage development inside the material, with the exception of impact at the highest energy (30 J) for which sudden drop right after the maximum force was observed. This is also confirmed by the force-displacement curve where an extensive plateau at maximum force suggests the occurrence of damage inside the PB. As shown in Fig. 4, the only type of superficial damage that was detected is a pronounced residual indentation which increased with increasing impact energy for both thin and thick specimens (Fig. 2). Residual dent depth is usually a key parameter which can be related to the residual strength and the internal damage occurring in materials after an impact event [51,52]. Comparing thin and thick laminates, the latter exhibited a larger dent depth up to $20 \mathrm{~J}$-impact, while the situation reversed for a $30 \mathrm{~J}$-impact. This can be ascribed to the higher localized contact stresses in thick specimens while in thinner sam- 
(a)

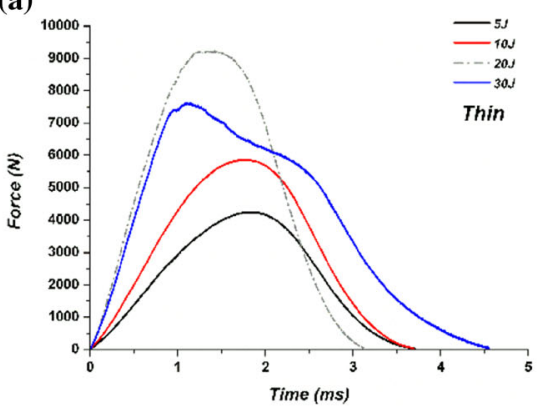

(b)

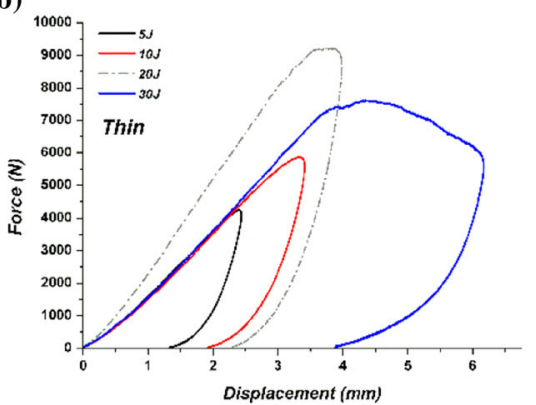

(c)

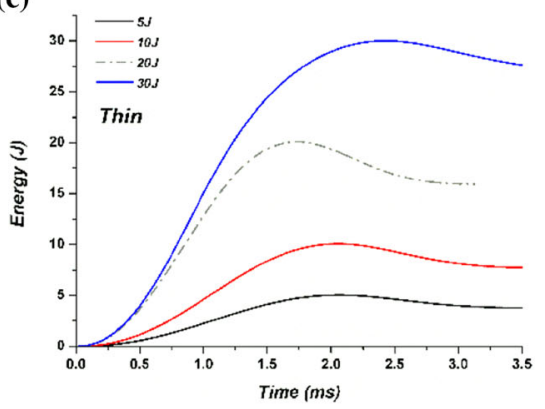

Fig. 3 Thin samples: a typical force versus time curves as a function of impact energy, $\mathbf{b}$ typical force versus displacement curves as a function of impact energy, and $\mathbf{c}$ typical energy versus time curves as a function of impact energy

(a)

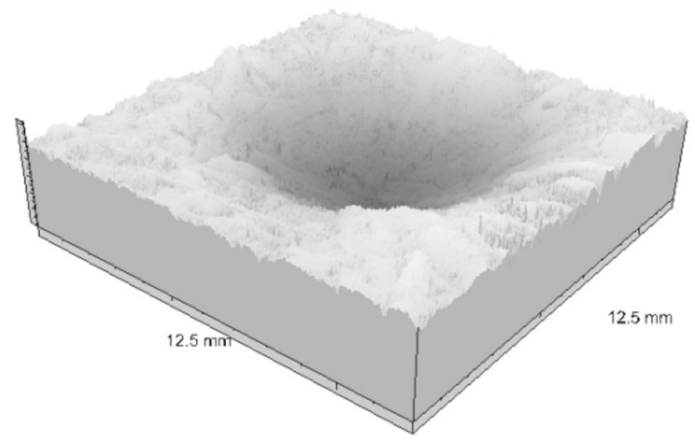

(c)

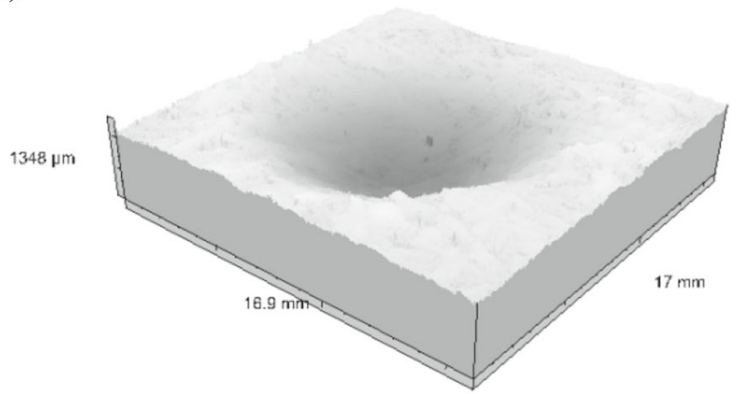

Fig. 4 3D view of thin samples as a function of increasing impact energy obtained by profilometer: a $5 \mathrm{~J}, \mathbf{b} 10 \mathrm{~J}, \mathbf{c} 20 \mathrm{~J}$ and d $30 \mathrm{~J}$. The reader should note that the in-plane dimensions represent the actual dimension of the scanned area (which is dependent on the extension of

ples membrane effects can be predominant. With increasing impact energy, the localized contact stress can reach a value high enough to induce damage also in thin samples, and $30 \mathrm{~J}$ is likely to be an impact energy suitable for causing significant damage.

Despite the pronounced indentation, thin PB samples were found to dissipate significant amount of energy as confirmed by the damage degree parameter (defined as the ratio of the unrecoverable energy dissipated by the system to the impact energy) [53] which varied from 0.75 up to 0.89 and still was found to be far from one where perforation occurs. (b)

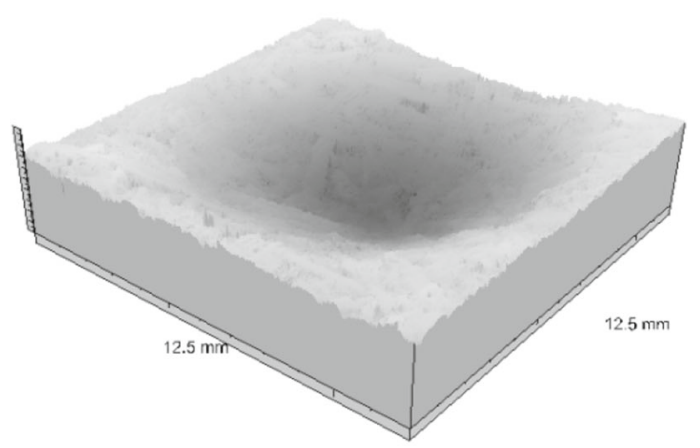

(d)

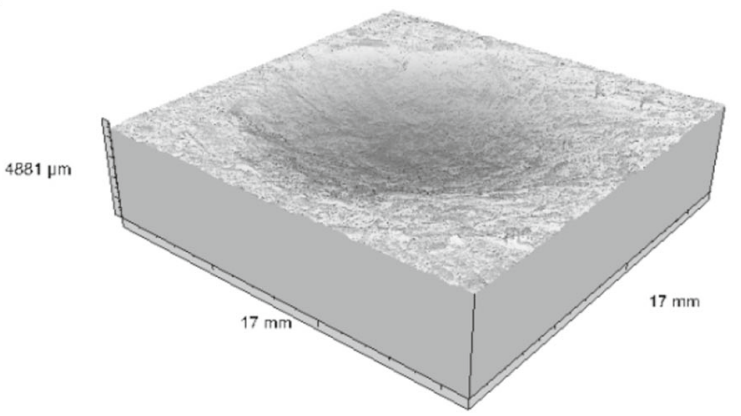

the damaged area with increasing impact energy), while the dimension in the thickness direction has been altered (stretched) in order to make more visible the penetration depth of the impactor

The Taylor-Hobson Talyscan 150 profilometer was able to retrieve the macro-defects produced by the impacts (Fig. 4). This type of equipment can be used as a preliminary nondestructive test [54] in order to measure the dent depth. The connection between the numerical simulation part and the NDT part can be found herein regarding the support provided by the profilometer, which is not able to detect subsurface defects, i.e., the task of the thermographic part. In fact, as can be seen in Sect. 4.3, the dent depth will be evaluated via numerical simulation after the construction and running of 
the model. A comparison between the numerical and experimental results will also be provided to the reader.

\section{Numerical Simulations}

The numerical simulation of the plates was performed via Comsol Multiphysics ${ }^{\circledR}$ using the finite element method (FEM). It may be noted that finite element models have the advantage of not transforming the mathematical operators, but they act on the integral form coming from the exact operator. Through FEM, it is possible to search the numerical solution of the complex partial differential equation (PDE); the importance of this step, i.e., (PDE) $\rightarrow$ (FEM), is due to the mathematical problem based on the solution - in the closed form - of the set of equations (PDE) which control the physics of real models. The transition from the geometric/analytic model to the numerical model occurs thanks to the weak solutions technique [55].

For the dynamic aspect of the modelling, the following set of governing equations was used:

$$
\begin{aligned}
\rho \frac{\partial^{2} \boldsymbol{u}}{\partial t^{2}} & =\nabla \cdot(\overline{\bar{F}} S)+\boldsymbol{F}_{v}, \\
\overline{\bar{F}} & =\overline{\bar{F}}+\nabla \boldsymbol{u}, \\
\overline{\bar{S}} & =\overline{\bar{S}}_{0}+\overline{\bar{C}}:\left(\bar{\varepsilon}-\bar{\varepsilon}_{0}-\overline{\varepsilon_{\text {inel }}}\right), \\
\bar{\varepsilon} & =\frac{1}{2}\left(\nabla u+(\nabla \boldsymbol{u})^{T}+(\nabla \boldsymbol{u})^{T} \nabla \boldsymbol{u}\right),
\end{aligned}
$$

where $\rho$ is the density, $\boldsymbol{u}$ is the displacement field, $S$ is the stress, $S_{0}$ is the initial stress, $C$ is the elasticity tensor, $\varepsilon$ is the strain, $\varepsilon_{0}$ is the initial strain, $\varepsilon_{\text {inel }}$ is the thermo-elastic strain, $\boldsymbol{F}_{v}$ is the volume force vector, $I$ is the identity matrix, $t$ is the time, and ()$^{T}$ is the transpose of a matrix [56]. The solution to the problem is not simple, considering the type of tensor $C$ and its $\varepsilon$. Indeed, these values must refer to an orthotropic material since SCB was used to build the layers. For the polyurethane resin based on castor oil, the behavior is isotropic; therefore, it is sufficient to provide the Young's modulus value, the Poisson's ratio and the density value. In addition, the SCB was assimilated with a linear elastic behavior, since the shape of the composite is like a mat, the fibres do not directly interact between them; therefore, the typical problems of mutual interactions outside the elastic range are not evident.

Thus, by solving the above equations and taking into account that Eq. 3 can be developed via the generalized Hooke's law, it is possible to obtain:

$\sigma^{i j}=C^{i j k l} \varepsilon_{k l}$,

where $\sigma$ is the tensor of the second order of the stress, $C$ is the elasticity tensor (linear elastic binding of the fourth order), $\varepsilon$ is the tensor of the second order of deformations, and $i, j, k, l$ are the indices of the tensor. The tensor $C$ is defined as follows:

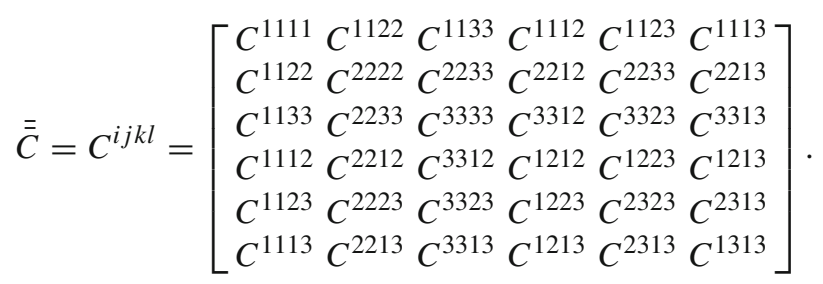

Since $C$ is symmetric (indeed, the second mixed derivatives of the elastic stress have similar indices but alternating), in the isotropic case can be obtained:

$$
\overline{\bar{C}}=\frac{E}{(1+v)(1-2 v)}\left[\begin{array}{cccccc}
1-v & v & 0 & 0 & 0 & 0 \\
v & 1-v & v & 0 & 0 & 0 \\
v & v & 1-v & 0 & 0 & 0 \\
0 & 0 & 0 & \frac{1-2 v}{2} & 0 & 0 \\
0 & 0 & 0 & 0 & \frac{1-2 v}{2} & 0 \\
0 & 0 & 0 & 0 & 0 & \frac{1-2 v}{2}
\end{array}\right] \text {, }
$$

where $v$ is the Poisson's ratio, and $E$ is the Young's modulus. Instead, for the orthotropic case, the tensor $C$ can be described in reverse form:

$$
\begin{aligned}
& \overline{\bar{C}}= \\
& {\left[\begin{array}{cccccc}
\frac{E_{x}^{2}\left(E_{z} v_{y z}^{2}-E_{y}\right)}{\text { Denom }} & \frac{E_{x} E_{y}\left(E_{z} v_{y z} v_{x z}+E_{y} v_{x y}\right)}{\text { Denom }} & -\frac{E_{x} E_{y} E_{z}\left(v_{x y} v_{y z}+v_{x z}\right)}{\text { Denom }} & 0 & 0 & 0 \\
0 & \frac{E_{y}^{2}\left(E_{z x}^{2} E_{x}\right)}{\text { Denom }} & \frac{E_{y}^{2}\left(E_{z} v_{x z}-E_{x}\right)}{\text { Denom }} & 0 & 0 & 0 \\
0 & 0 & \frac{E_{y} E_{z}\left(E_{y} v_{x y}^{2}-E_{x}\right)}{\text { Denom }} & 0 & 0 & 0 \\
0 & 0 & 0 & G_{x y} & 0 & 0 \\
0 & 0 & 0 & 0 & G_{y z} & 0 \\
0 & 0 & 0 & 0 & 0 & G_{x z}
\end{array}\right],}
\end{aligned}
$$

where $E$ is the parameter for which $E$ represents the "values of the global directions" along the $x, y, z$ axes as indicated in Fig. 5e, $G$ indicates the shear modulus, while Denom is the following [57]:

$$
\begin{aligned}
\text { Denom }= & E_{y} E_{z} v_{x z}^{2}-E_{x} E_{y} \\
& +2 v_{x y} v_{y z} v_{x z} E_{y} E_{z}+E_{x} E_{z} v_{x z}^{2}+E_{y}^{2} v_{x y}^{2} .
\end{aligned}
$$

By considering the Voigt's notation for the computational use, the indices of $C$ in the tensor notation can be converted [58] in:

$$
\left[\begin{array}{c}
11 \\
22 \\
33 \\
12,21 \\
23,32 \\
13,31
\end{array}\right] \rightarrow\left[\begin{array}{l}
1 \\
2 \\
3 \\
4 \\
5 \\
6
\end{array}\right] \rightarrow\left[\begin{array}{c}
x \\
y \\
z \\
x y \\
y z \\
x z
\end{array}\right]
$$


where $x, y, z, x y, y z$ and $x z$ are the directions of the main trio explained by matrix notation; via simple steps, it is possible to obtain the extended orthotropic notation:

$$
\begin{gathered}
{\left[\begin{array}{c}
S_{x} \\
S_{y} \\
S_{z} \\
S_{x y} \\
S_{y z} \\
S_{x z}
\end{array}\right]=\left[\begin{array}{c}
S_{x} \\
S_{y} \\
S_{z} \\
S_{x y} \\
S_{y z} \\
S_{x z}
\end{array}\right]_{0}} \\
+\overline{\bar{C}}\left(\left[\begin{array}{c}
\varepsilon_{x} \\
\varepsilon_{y} \\
\varepsilon_{z} \\
2 \varepsilon_{x y} \\
2 \varepsilon_{y z} \\
2 \varepsilon_{x z}
\end{array}\right]-\left[\begin{array}{c}
\varepsilon_{x} \\
\varepsilon_{y} \\
\varepsilon_{z} \\
2 \varepsilon_{x y} \\
2 \varepsilon_{y z} \\
2 \varepsilon_{x z}
\end{array}\right]_{0}+\text { void }\right),
\end{gathered}
$$

where $S$ is the stress, $S_{0}$ is the initial stress, $\varepsilon$ is the strain, all three expressed along specific directions (i.e., $x, y, z, x y, y z, x z)$. When Eq. 11 is obtained, step by step Eqs. 2 and 3 can be calculated and, finally, via the evaluation of the volume strengths $\boldsymbol{F} v$, it is possible to iteratively solve Eq. 1.

\subsection{Construction of the Model}

The geometric reproduction of the sample is extremely complex to replicate as a model, because of the random arrangement of the elements constituting the individual ply. With respect to the in-plane reproduction, taking into account the random orientation, similarly to a matrix approach, it is possible to consider that a representative part of the superficial layer is a necessary and sufficient condition for the representation of the whole sample. A dimension of the representative part was therefore identified equal to one order of magnitude lower, i.e., $7 \times 7 \mathrm{~mm}^{2}$. For the out-of-plane reproduction, in order to avoid the repetition of the representative part of bagasse, it was considered appropriate to rotate the sub-area of $\pi / 2$ with respect to the plane, as well as overlap this area with the purpose of obtaining the subsequent plies. This procedure avoids the periodic repeatability of the mat that may invalidate the numerical approach, both in-plane and out-of-plane.

In Fig. 5a, b, c, d, and e the images of the samples impacted at $5,10,20,30 \mathrm{~J}$ and the reconstruction of the representative area via segmentation algorithm are reported, respectively. The representative area is magnified in Fig. 5c.

Taking into account the type of stress due to the impactor, it is evident that the test imposes the reciprocal sliding of the plies, making the latter the predominant problem to be analyzed. Considering the structural characteristics of the materials that form the final sample, it is possible to notice that the polyurethane resin based on castor oil is the weak element of the structure.

In Table 2, the physical and mechanical properties of the materials constituting the impactor are reported along with those of the materials constituting the composite $[59,60]$.

Thus, it is important to analyze the sliding conditions between two layers of the sample which are in contact with each other. Since the samples have a thickness equal to $16 \mathrm{~mm}$ and considering that the type of support is tubular with a diameter of $40 \mathrm{~mm}$, the stress distribution along the thickness of the composite material will not generate detectable stress variations in the depth. Therefore, the idea was to model only two layers of SCB and polyurethane resin based on castor oil forcing them through a sliding action.

Bearing in mind the relevant regulations for structural loads, the lap shear strength test of the ASTM D3163-01 (titled: determining strength of adhesively bonded rigid plastic lap-shear joints in shear by tension loading) suggests to verify the sliding between the plies in order to derive the characteristics of the composite to be obtained. This test recommends a partial overlap of $50 \%$ of two consecutive layers.

In the present case, this method is not suitable due to the poor structural performance of a single layer subjected to bending [61]. If it will be modeled, there would be only the contribution of the resin to support the flexural part beyond the $50 \%$ in adhesion. In order to minimize this problem, (a)

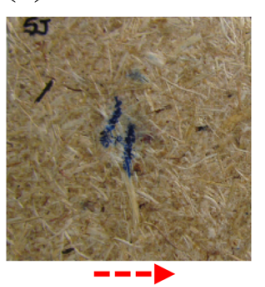

(b)

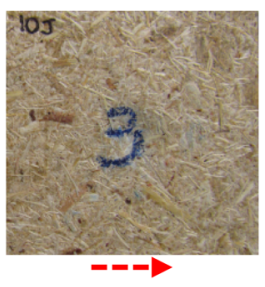

(c)

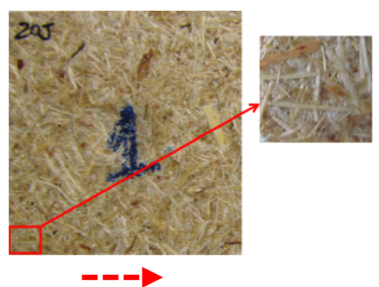

(d)

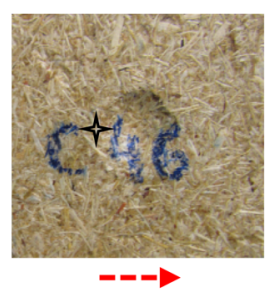

(e)

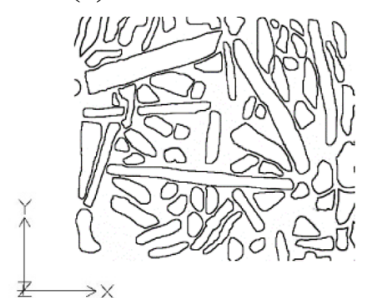

Fig. 5 SCB samples impacted at: a 5 J, b $10 \mathrm{~J}, \mathbf{c} 20 \mathrm{~J}, \mathbf{d} 30 \mathrm{~J}$ and e the segmented image of the representative area magnified in $\mathbf{c}$. In the latter, the global directions analysed in Comsol Multiphysics ${ }^{\circledR}$ are reported.
The red arrows indicate the line direction for heating used during the line scanning thermography (LSgT) technique (Color figure online) 
Table 2 Mechanical properties of the materials constituting the composite

\begin{tabular}{|c|c|c|c|c|c|c|}
\hline Materials & $\begin{array}{l}\text { Density } \\
\left(\mathrm{kg} / \mathrm{m}^{3}\right)\end{array}$ & $\begin{array}{l}\text { Young's modulus } \\
\text { isotropic (MPa) }\end{array}$ & $\begin{array}{l}\text { Young's modulus } \\
\text { of elasticity along } \\
\text { the three }(1,2,3) \\
\text { directions } \\
\text { of the tensor }(\mathrm{T}) \\
\text { (MPa) T1-T2-T3 }\end{array}$ & $\begin{array}{l}\text { Modulus of } \\
\text { rupture (MPa) } \\
\text { along the three } \\
(1,2,3) \text { directions } \\
\text { of the tensor } \\
\text { (T) T1-T2-T3 }\end{array}$ & $\begin{array}{l}\text { Poisson's ratio } \\
\text { along the three } \\
(1,2,3) \text { directions } \\
\text { of the tensor }(\mathrm{T}) \\
\mathrm{T} 1-\mathrm{T} 2-\mathrm{T} 3\end{array}$ & $\begin{array}{l}\text { Shear modulus } \\
\text { (GPa) along the } \\
\text { three (1, 2, 3) } \\
\text { directions } \\
\text { of the tensor } \\
\text { (T) T1-T2-T3 }\end{array}$ \\
\hline Bagasse & 520 & - & $2.85-2.85-1.85$ & $21.2-22.6-14.8$ & $0.25-0.25-0.45$ & $3.5-3.5-2.6$ \\
\hline Adhesive & 1200 & 1.5 & - & - & 0.33 & - \\
\hline Impactor & 7810 & 205 & - & - & 0.3 & - \\
\hline
\end{tabular}

(a)

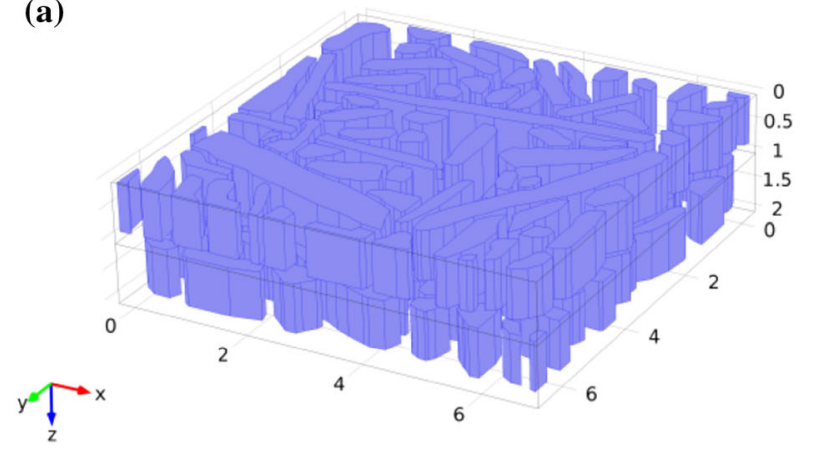

(b)

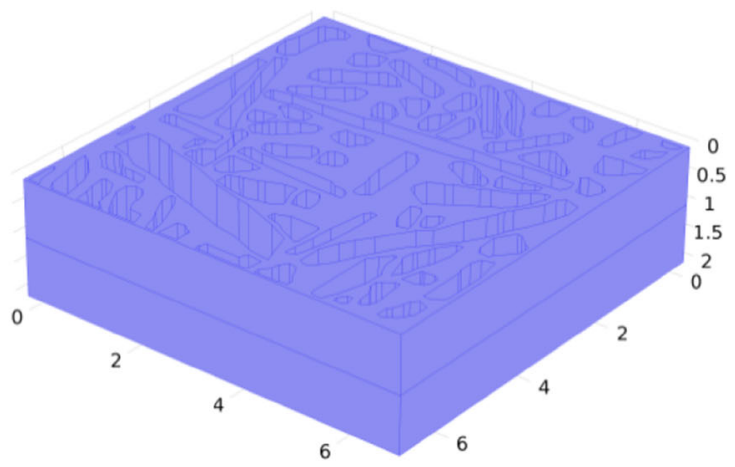

Fig. 6 Geometry for the FEM simulation of the representative area, with two plies stressed by sliding force: a elements of the representative area (only bagasse), and $\mathbf{b}$ ply filled with the resin

the layers were entirely overlapped and exposed to a sliding force, as shown in Fig. 6 a.

The aim of this analysis is to derive the structural parameters of two consecutive layers, bearing in mind the limitations of the lap shear strength and of the polyurethane resin based on castor oil. After the simulation, the $E$ and $G$ values in the three directions, as well as the Poisson's ratio were calculated. Given the particular interaction between the materials constituting the samples, due to the different nature (orthotropic for the SCB and isotropic for the resin), two analyses were developed in parallel. The first one considering the classic method, and the second one, which is a numerical method for verification. In the following (Eq. 12), the values assigned to the orthotropic component are summarized.

$$
\begin{aligned}
& \text { Young's modulus }\left[\begin{array}{c}
122.7 e 9 \\
10.1 e 9 \\
10.1 e 9
\end{array}\right] \mathrm{Pa}, \\
& \text { Poisson's ratio }\left[\begin{array}{c}
0.25 \\
0.45 \\
0.25
\end{array}\right] \\
& \text { Shear modulus }\left[\begin{array}{c}
5.5 e 9 \\
3.7 e 9 \\
5.5 e 9
\end{array}\right] \mathrm{Pa} .
\end{aligned}
$$

On the other hand, the isotropic component is:

Young's modulus $\left[\begin{array}{l}2.85 e 6 \\ 2.85 e 6 \\ 1.85 e 6\end{array}\right] \mathrm{Pa}$,

Poisson's ratio $\left[\begin{array}{l}0.25 \\ 0.25 \\ 0.45\end{array}\right]$,

Shear modulus $\left[\begin{array}{c}3.5 e 6 \\ 3.5 e 6 \\ 2 e 6\end{array}\right] \mathrm{Pa}$.

Therefore, the stress tensor is:

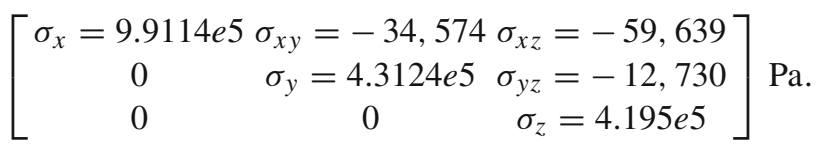

Now, it is possible to calculate the corresponding $E$ values:

$$
\begin{aligned}
& E=\frac{\sigma_{11}-v\left(\sigma_{22}+\sigma_{33}\right)}{\varepsilon_{11}}=1.44 e 5 \mathrm{~Pa}, \\
& E=\frac{\sigma_{33}-v\left(\sigma_{11}+\sigma_{22}\right)}{\varepsilon_{33}}=1.38 e 5 \mathrm{~Pa} .
\end{aligned}
$$


Taking into account the difference between the $E$ values, the smaller value was used for conservative purposes. Similarly, the $G$ value is:

$G=\frac{1}{2 \varepsilon_{13}} \sigma_{13}=0.56 e 5 \mathrm{~Pa}$,

where $\sigma$ is the tensor of the second order of the stress and $\varepsilon$ is the tensor of the second order of the strain, both expressed along specific directions (i.e., 1, 2, 3, 12, 23, 13).

Concerning the density value, it was experimentally estimated since the samples may come from different plates. Table 3 summarizes the main properties:
In the following, the values obtained from the numerical simulation (Fig. 7) of the interesting parameters (Figs. 8, 9) of the composite material are shown.

Considering the comparative evaluation of the values obtained from the simulation and calculation with the classical method (von Mises), a slight difference can be detected [62]. The data obtained with the classical approach are more conservative, and this may be due to the mathematical model that is not optimized for a specific case such as the numerical one. Working with the values obtained, it is possible to build a satisfactory model, by treating the plate like a continuous isotropic.

Table 3 Mechanical properties of the composite as a whole (equivalent composite material)

\begin{tabular}{lllll}
\hline Material & Density $\left(\mathrm{kg} / \mathrm{m}^{3}\right)$ & $\begin{array}{l}\text { Young's modulus } \\
\text { isotropic }(\mathrm{Pa})\end{array}$ & $\begin{array}{l}\text { Poisson's } \\
\text { ratio }\end{array}$ & $\begin{array}{l}\text { Shear } \\
\text { modulus }(\mathrm{Pa})\end{array}$ \\
\hline Composite & $\approx 800$ & $1.38 \mathrm{e} 5$ & 0.33 & $0.56 \mathrm{e} 5$ \\
\hline
\end{tabular}

(a)

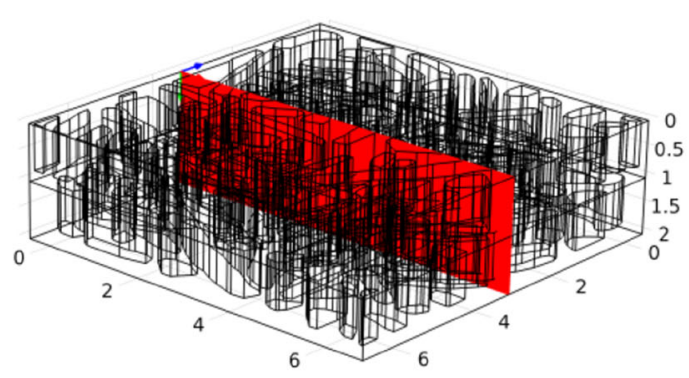

(b)
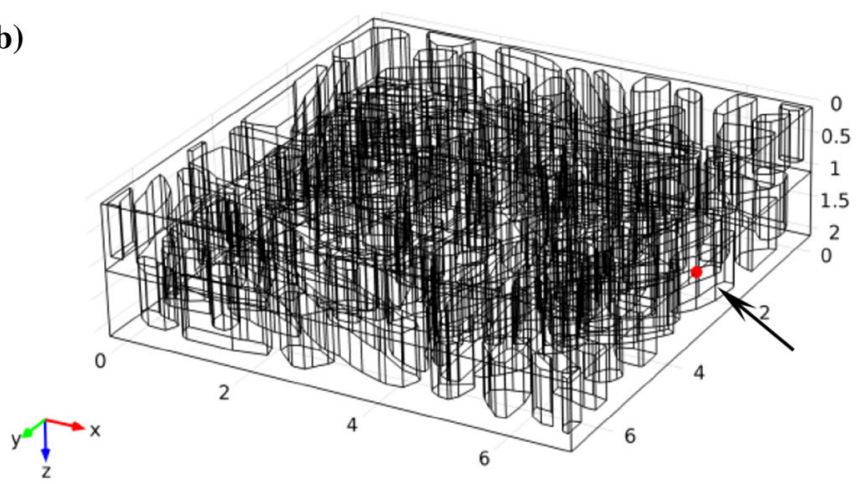<smiles>[Y]C1CCC1</smiles>

Fig. 7 Images of the representative area: a analysis of the scrolling plane (in red), and b point of analysis (in red-marked by an arrow) for the evaluation of the centralization of the power (Color figure online)

(a)

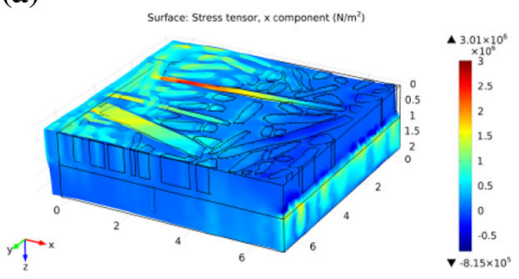

(d)

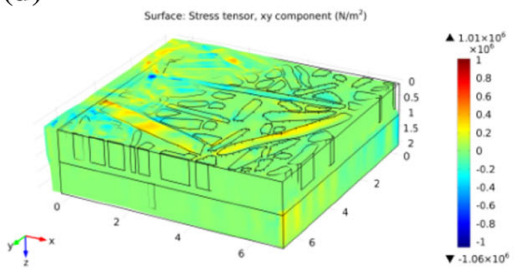

(b)

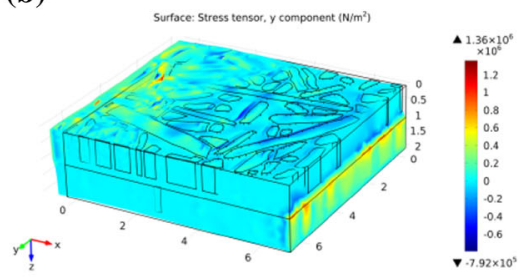

(e)

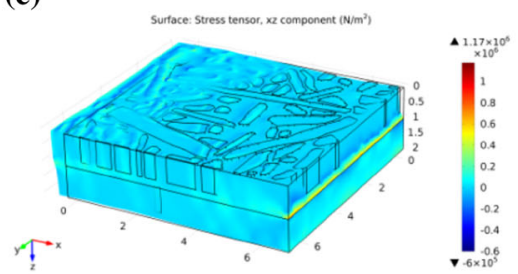

(c)

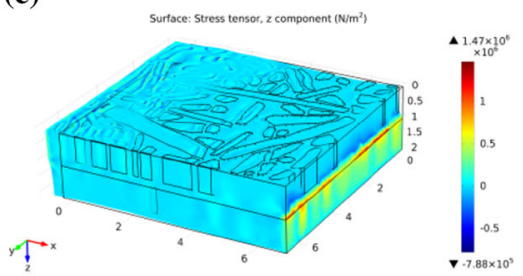

(f)

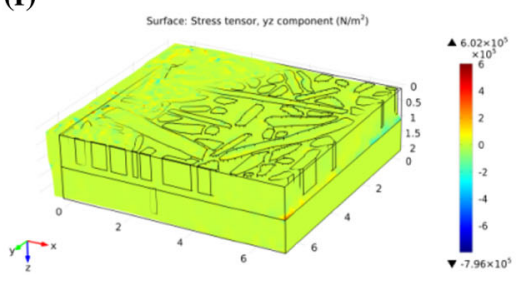

Fig. 8 Stress tensor in the characteristic components: a Component 11, b Component 22, c Component 33, d Component 12, e Component 13, and f Component 23 
(a)

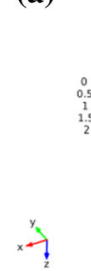

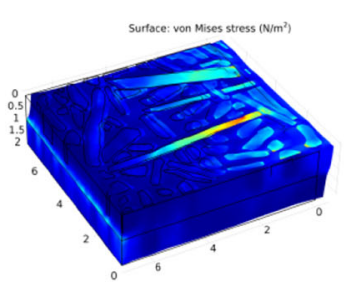

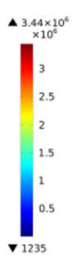

(b)

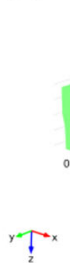

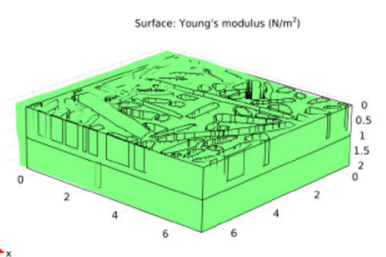

(c)

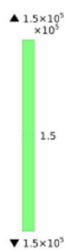

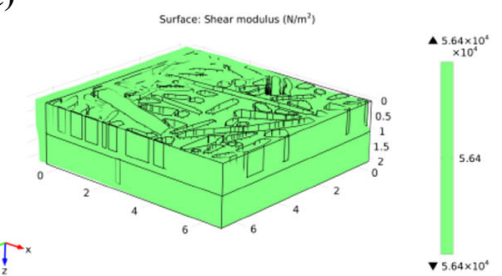

Fig. 9 a Stress of von Mises (top-of-view), b global Young's modulus (considering all of the equivalent isotropic sample), and $\mathbf{c}$ global shear modulus (considering all of the equivalent isotropic sample)

(a)

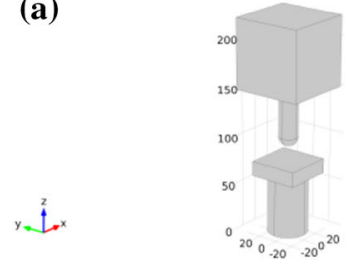

(b)

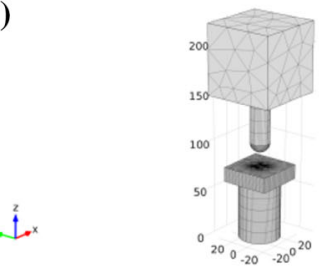

(c)

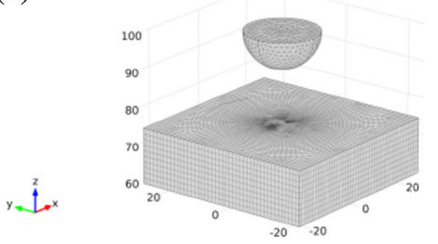

Fig. 10 a Structure for the FEM simulation, $\mathbf{b}$ wireframe mesh, and $\mathbf{c}$ detail of the impactor/plate

\subsection{Geometry and Mesh}

The initial height between the plate and the impactor was dependent on the impact energy level. The system for the impact has a weight of $3 \mathrm{~kg}$, and a diameter of the impactor equal to $20 \mathrm{~mm}$. The latter was dropped down by gravity. Therefore, an impulsive loading was transferred to the samples. The modelling involves the reconstruction of the experimental set-up, starting from the support system which is fundamental in order to reproduce the right boundary conditions. The latter was prepared using a hollow cylinder having an internal diameter equal to $40 \mathrm{~mm}$; the samples were placed on the top side. Taking into account the computational cost, and considering the numerical contribution of the support focused on the plate-support boundary conditions, it was considered useful to model the physics of the element like a rigid body. This idea led to a further advantage, namely, avoiding the calculation at compression of the cylinder, indispensable if considered like an elastic domain. The machine component constituting the impactor was treated as a hemisphere for the impact zone, as a cylinder for the central area and, for the upper part, a parallelepiped-similar to a carriage-is present with a kinematic function. Figure 10a shows the geometry selected for the analysis, while Fig. 10b, c clarify the selected mesh.

Figure 10b, $\mathrm{c}$ show the different implementation of the mesh in relation to the individual elements. For the base plate, a swept geometry was used. This is justified by the axial symmetry. Despite this being a hollow structure subjected to a buckling phenomenon, it is possible to notice an elongation of the nodal elements along the shaft. Such a construction is, however, feasible given that the item under analysis will be considered like a rigid body. Similarly, for the mesh of the plate a radial pattern was selected. This choice is linked to two reasons: (a) to focus the nodal elements in the impact area, and (b) to give priority to the nodal elements along the circumferences, in order to ensure that the boundary conditions inherent to the support are consistent. Regarding the plate, along the $z$ axis a nodal spacing directly proportional to the real plies was chosen. Instead, for the sphere a tetrahedral mode having a size finer was selected. In the following (Table 4), the parameters under the category finer are specified in order to allow the reproduction of the simulation for an interested reader.

The need to gradually evaluate the transmission of the impact to the sample resulted in a thickening of the mesh in that area. For the cylindrical shaft of the impactor, a swept mesh thinned out along the $z$ axis was used. Indeed, the latter is reduced in the free length of inflection and, moreover, geometrically it is a full piece. Regarding the impactor, the tetrahedral mode with an extremely coarse size is more than sufficient in order to analyse both the scrolling phenomenon and the gravitational field in which the parallelepiped was involved. In this case, the multibody dynamics module set with an elastic material for the plate and for the impactor was used. In addition, the gravitational field effect was set for the whole system, while regarding the contact phase, a contact pair working through a penalty function-calibrated for the purpose-was used. The type of the numerical solver was a direct $\rightarrow$ (MUMPS) $\rightarrow$ segregated. The above details are reported in order to make the process self-explanatory.

The mesh convergence was produced by an automatic debugger that was activated via the Build Selected. Therefore, the convergence was automatically estimated; otherwise, the mesh would be completed with a warning or would not be generated. Although analyses designed to study the 
Table 4 Mesh setting parameters: (a) values for the base plate (impact analysis), (b) values for the plate (impact analysis), (c) values for the spherical zone of the impactor (impact analysis), (d) values for the shaft area of the impactor (impact analysis), (e) values for the mass of the impactor (impact analysis), and (f) values for the modeling of the detachment condition (detachment analysis)
Specific

Dimension (mm)

(a)

Swept

Example dimension of the mesh $\rightarrow$ dimension selected $\rightarrow$ customization process

Size $\rightarrow$ extremely fine $\rightarrow$ custom

Maximum element size $\quad 1.5$

Minimum element size $\quad 0.01$

Maximum element growth rate $\quad 1.3$

$\begin{array}{ll}\text { Curvature factor } & 0.38\end{array}$

Resolution of narrow regions 1

(b)

Swept

Distribution $\rightarrow 10$

Size $\rightarrow$ extremely fine $\rightarrow$ custom

Maximum element size

1.5

Minimum element size

0.02

Maximum element growth rate

1

Curvature factor

Resolution of narrow regions

1

(c)

Free tetrahedral

Size $\rightarrow$ coarse $\rightarrow$ custom

Maximum element size

Minimum element size

Maximum element growth rate

1.6

Curvature factor

0.7

Resolution of narrow regions

0.4

(d)

Swept

Distribution $\rightarrow 4$

Size $\rightarrow$ coarse $\rightarrow$ custom

Maximum element size

Minimum element size

5.85

Maximum element growth rate

1.6

Curvature factor

0.7

Resolution of narrow regions

0.4

(e)

Free tetrahedral

Size $\rightarrow$ extra coarse $\rightarrow$ predefined

Maximum element size

Minimum element size

11.3

Maximum element growth rate

1.85

Curvature factor

0.9

Resolution of narrow regions 
Table 4 continued

(f)

Free tetrahedral

Size $\rightarrow$ finer $\rightarrow$ custom

$\begin{array}{lr}\text { Maximum element size } & 1.07\end{array}$

$\begin{array}{ll}\text { Minimum element size } & 0.014\end{array}$

Maximum element growth rate $\quad 1.6$

$\begin{array}{ll}\text { Curvature factor } & 0.7\end{array}$

$\begin{array}{ll}\text { Resolution of narrow regions } & 0.4\end{array}$

(a)

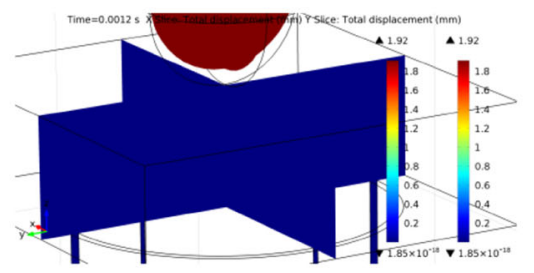

(b)

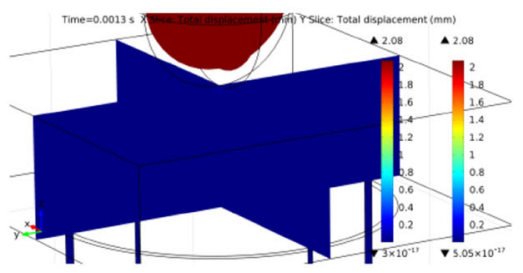

(c)

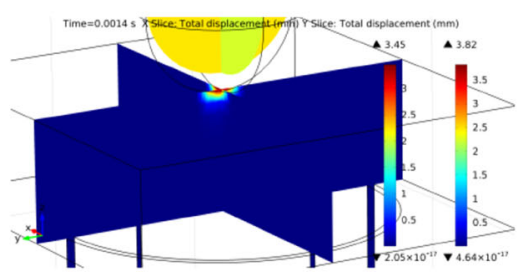

(d)

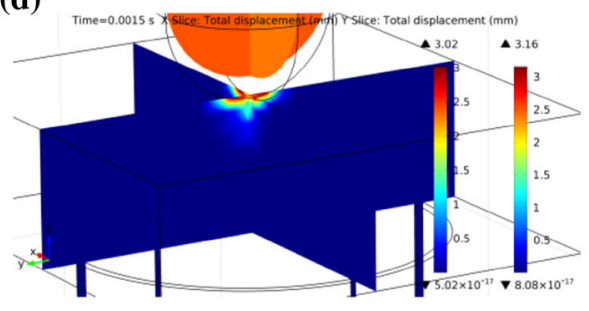

(e)

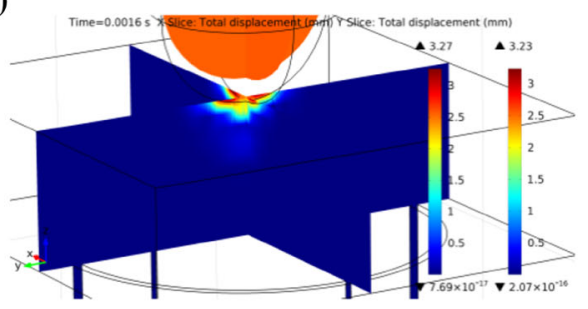

Fig. 11 Slices $\rightarrow$ displacement at fixed time instant: a $0.0012 \mathrm{~s}, \mathbf{b} 0.0013 \mathrm{~s}, \mathbf{c} 0.0014 \mathrm{~s}, \mathbf{d} 0.0015 \mathrm{~s}$, and e $0.0016 \mathrm{~s}$

behaviour of the convergence of the numerical model during the changing of the mesh node numbers exist, typically, the latter are used in order to evaluate the variation of the quality of convergence of the numerical model considering the variation of the number of nodes. In the present case, this type of analyses is not suitable because the coupled geometries have dimensions of the same order of magnitude; in addition, the decrease of the obtainable nodes, does not appreciably reduce the computational cost.

\subsection{Numerical Simulation Results}

\subsubsection{Case: 5 J}

For this impact energy the height of release of the impactor was $170 \mathrm{~mm}$. The instantaneous velocity detected at the impactor/surface interface was equal to $1.59 \mathrm{~m} / \mathrm{s}$, i.e., in the numerical model the gravity was implemented and a speed of $1.59 \mathrm{~m} / \mathrm{s}$ before impact was obtained. Considering the material and geometrical quantities invariant, therefore, the numerical model is the same in all four cases. The substan- tial difference among the cases are: (a) the density of the sample, (b) the impact velocity $\boldsymbol{u}$, and (c) the transferred energy. In case of laceration and/or interpenetration, since the model was built for the Coleman-Noll hypothesis, the impossibility of convergence during the time of calculation is obtained. From this consideration it is evident that a possible non-convergence is not exclusively attributable to a lack of continuity in the material. In the present case, the model arrived at convergence in a period of time between 0 and $0.0018 \mathrm{~s}$. During the modelling, the entire approaching phase of the impactor was not reproduced in order to reduce the computational cost. The problem was solved by considering the zero time when the impactor arrived at a distance of $2 \mathrm{~mm}$ from the plate. Also for the displacement, the zero was set at $2 \mathrm{~mm}$. The different position compared to the real zero, i.e., 0, was computed by considering the initial conditions suitably modified at the end of the iteration.

Figure 11a-c show the different physical quantities, starting from the key stage up to the end of the salient phases. Figure 11d, e indicate the trends of displacement and maximum acceleration, respectively, that the composite structure 
(a)

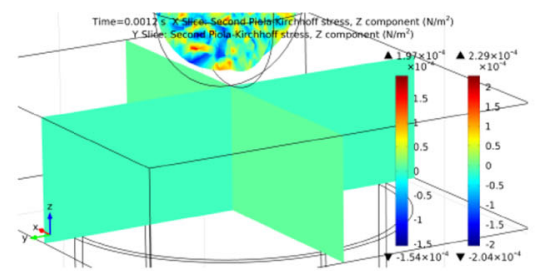

(d)

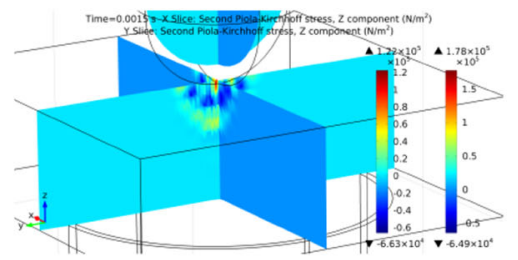

(b)

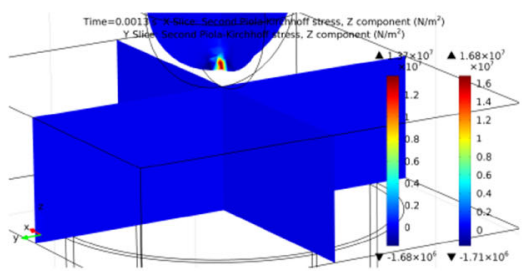

(e)

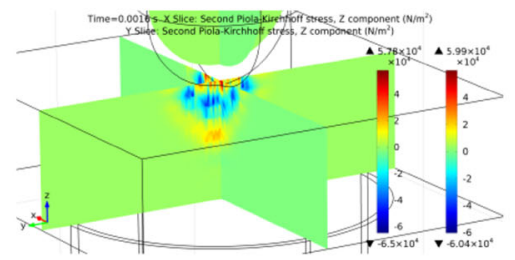

(c)

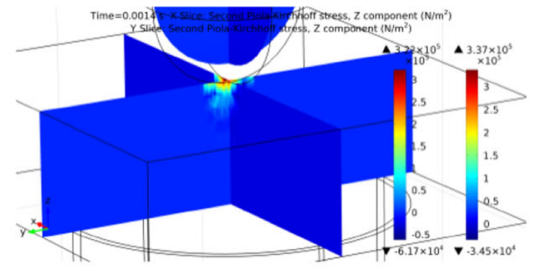

(f)

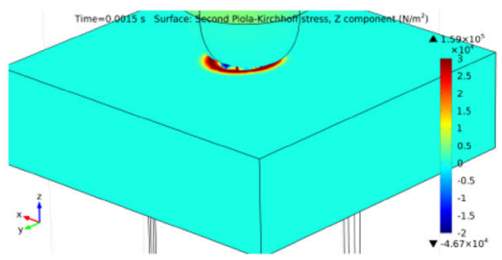

Fig. 12 Slices $\rightarrow$ 2nd Piola-Kirchhoff at fixed time instant: a $0.0012 \mathrm{~s}, \mathbf{b} 0.0013 \mathrm{~s}, \mathbf{c} 0.0014 \mathrm{~s}, \mathbf{d} 0.0015 \mathrm{~s}, \mathbf{e} 0.0016 \mathrm{~s}$, and $\mathbf{f}$ state of critical stress

experiences. These trends were obtained without considering the structures present outside the test plate.

Figure 11a represents the incipient stage. The scale bar of the displacement shows a value of $1.92 \mathrm{~mm}$ which corresponds to a distance impactor-plate equal to 800ths of a millimeter. Figure 11b, c show an advancement of the impactor in the material up to $0.0014 \mathrm{~s}$, with an estimated global depth in the plate of $3.45 \mathrm{~mm}$, which corresponds to $1.45 \mathrm{~mm}$ effective depth in the material. Note that the effect of the permanent static deflection of the whole sample is also present. Figure 11d, e show an elastic return of the impactor.

From Fig. 12a, the presence of two section planes parallel to the reference axes and passing through the impact zone is shown. In the first time instant, corresponding to the incipient contact, a stress present on the impactor can be noted. As evidenced by the scale bars, this effect was not due to structural load, but can be attributed to numerical effects linked both to the displacement and to the forward speed of the structure. The maximum value of stress was reached in Fig. 12e for a time of $0.0016 \mathrm{~s}$. In all the previous cases, it is possible to observe a coherent distribution of the stress in the structure. In Fig. 12f, the second tensor of Piola-Kirchhoff is shown, with a large global/local deformation that affects the impact zone. The behaviour of the rigid support should be highlighted, since it does not show stress states, considering that they were not calculated.

In the following, the average of the global displacement related to the composite plate is shown (Fig. 13a), along with the trend of the local acceleration as a function of time (Fig. 13b). In particular, Fig. 13a provides the permanent static deflection that the sample experiences at the end of the impact, while Fig. 13b shows the curve of the absolute maximum acceleration linked to the impact zone.

\subsubsection{Case: $10 \mathrm{~J}$}

In this case the height of release of the impactor was $340 \mathrm{~mm}$. The instantaneous velocity detected at the impactor/surface interface was equal to $2.58 \mathrm{~m} / \mathrm{s}$. In the present case, the model arrived at convergence in a period of time between 0 and $0.0018 \mathrm{~s}$. The zero time, i.e., 0, was considered when the impactor arrived at a distance of $2 \mathrm{~mm}$ from the plate. Also for the displacement, the zero was set at $2 \mathrm{~mm}$. The different position with respect to the real zero, i.e., 0, was balanced by considering the initial conditions suitably modified at the end of the iteration. Figure $14 \mathrm{a}-\mathrm{c}$ show the different physical quantities, starting from the key stage up to the end of the salient phases. Figure $14 d$, e indicate the trends of displacement and maximum acceleration, respectively, that the composite structure undergoes. These trends were obtained without considering the structures present outside the test plate.

Figure $14 \mathrm{a}$ represents the incipient stage. The scale bar of the displacement shows a value of $2.07 \mathrm{~mm}$ which corresponds to a distance impactor-plate equal to 700ths of a millimeter. Figure 14b-e show an advancement of the impactor in the material up to $0.0016 \mathrm{~s}$, with an estimated global depth in the plate of $4.14 \mathrm{~mm}$, which corresponds to $2.14 \mathrm{~mm}$. Note that the effect of the permanent static deflection of the whole sample is also present.

From Fig. 15a, the presence of two section planes parallel to the reference axes and passing through the impact zone is shown. Also in this case, in the first time instant, corresponding to the incipient contact, a stress present on the impactor can be noted. However, the maximum value of stress was reached at $0.0016 \mathrm{~s}$ (Fig. 15e). In all of the previous cases, it is possible to observe a coherent distribution of the stress in the structure. 
(a)

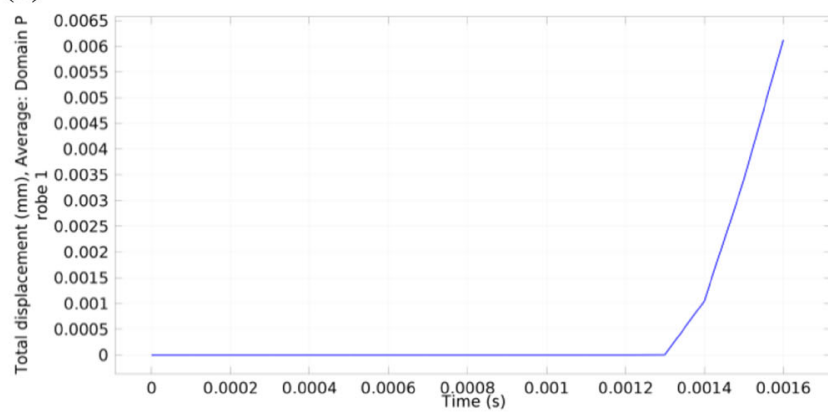

(b)

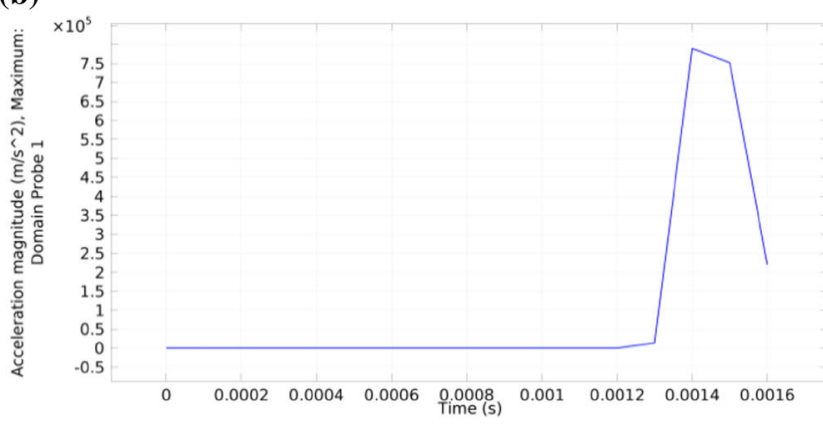

Fig. 13 a Trend of the displacement inherent to the composite plate, and $\mathbf{b}$ trend of the acceleration inherent to the composite plate

(a)

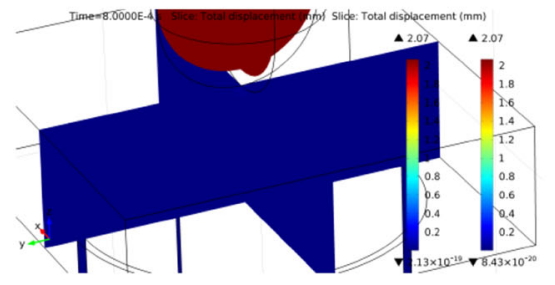

(b)

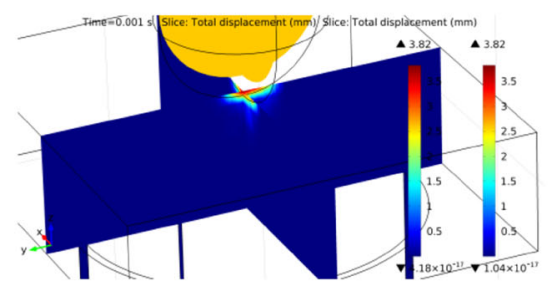

(c)

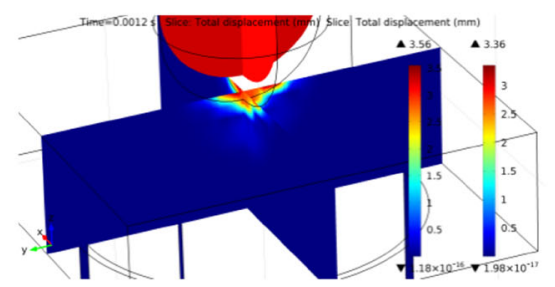

(d)

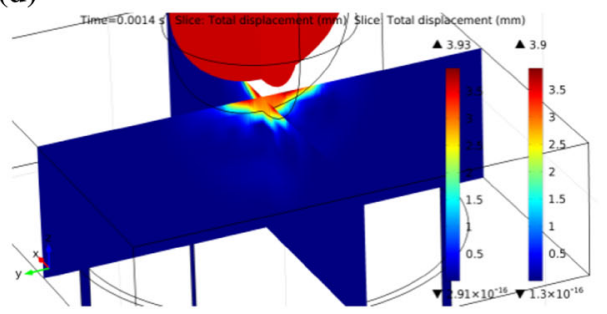

(e)

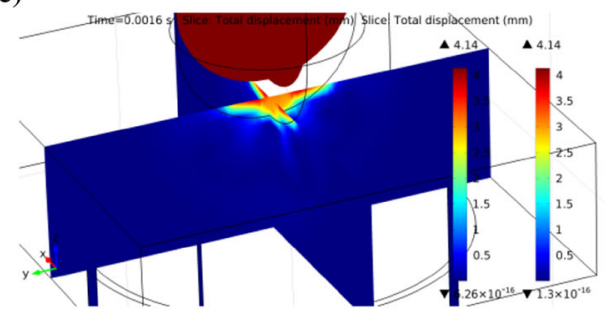

Fig. 14 Slices $\rightarrow$ displacement at fixed time instant: a $0.0008 \mathrm{~s}, \mathbf{b} 0.001 \mathrm{~s}, \mathbf{c} 0.0012 \mathrm{~s}, \mathbf{d} 0.0014 \mathrm{~s}$, and e $0.0016 \mathrm{~s}$

(a)

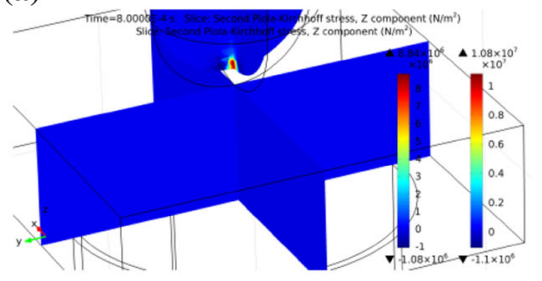

(d)

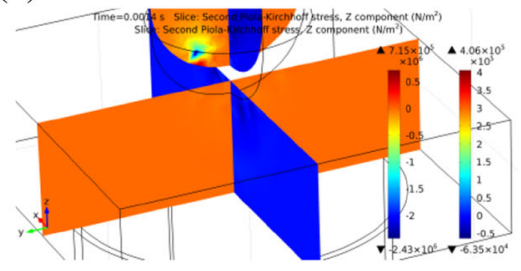

(b)

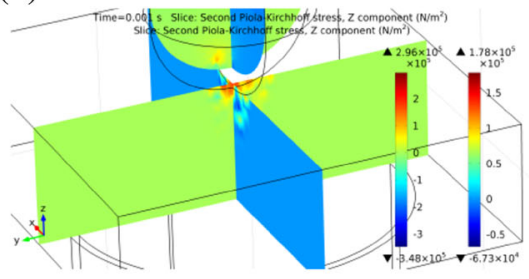

(e)

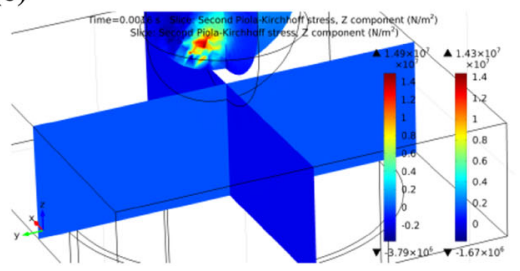

(c)

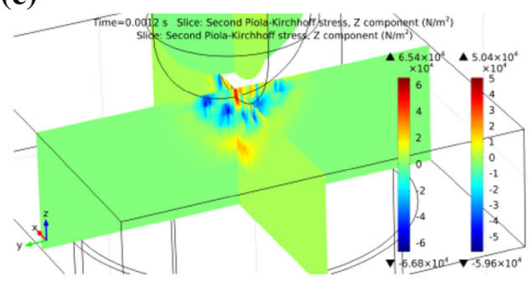

(f)

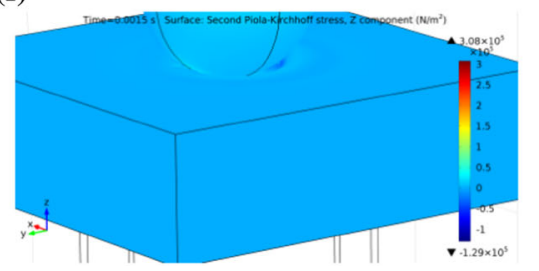

Fig. 15 Slices $\rightarrow$ 2nd Piola-Kirchhoff at fixed time instant: a $0.0008 \mathrm{~s}, \mathbf{b} 0.001 \mathrm{~s}, \mathbf{c} 0.0012 \mathrm{~s}, \mathbf{d} 0.0014 \mathrm{~s}, \mathbf{e} 0.0016 \mathrm{~s}$, and $\mathbf{f}$ state of critical stress 
(a)

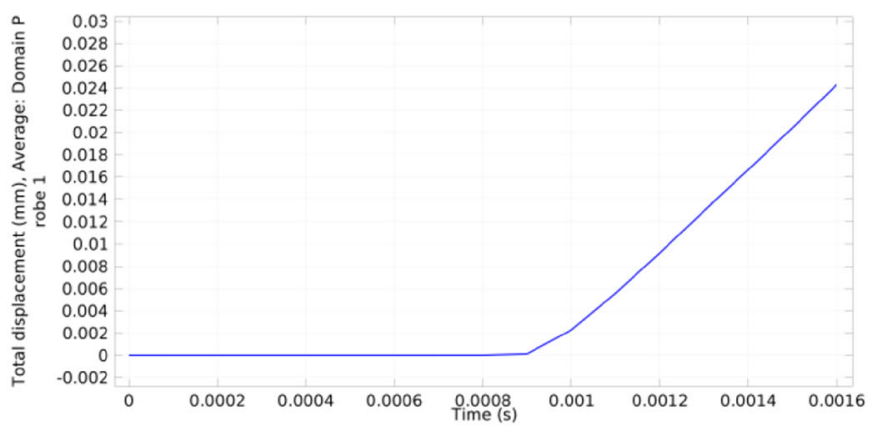

(b)

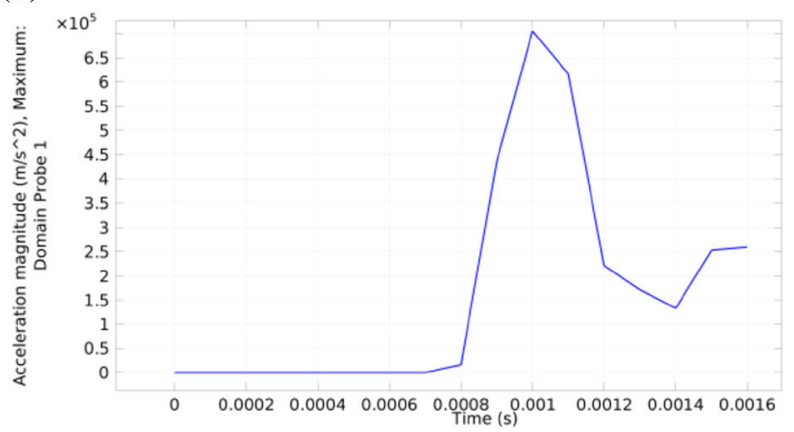

Fig. 16 a Trend of the displacement inherent to the composite plate, and $\mathbf{b}$ trend of the acceleration inherent to the composite plate

Table 5 Comparison between the experimental and calculated dent depth and the \% error

\begin{tabular}{llll}
\hline Samples $(\mathrm{J})$ & $\begin{array}{l}\text { Dent depth } \\
\text { experimental } \\
(\mu \mathrm{m})\end{array}$ & $\begin{array}{l}\text { Dent depth obtained } \\
\text { by Comsol } \\
\text { Multiphysics }\end{array}$ & \% Errors \\
$(\mu \mathrm{m})$ & \\
\hline 5 & 498 & 390 & 21.69 \\
10 & 622 & 700 & 11.14 \\
20 & 976 & 810 & 17.01 \\
30 & 1696 & 1560 & 8.01 \\
\hline
\end{tabular}

The concentration of the maximum peak of stress on the impactor highlights its rebound effect. On the latter, the structural loading effect and the reversal of the direction of motion were summed.

In Fig. 15f, the second tensor of Piola-Kirchhoff is shown, with a large global/local deformation that interests the impact zone. The behaviour of the rigid support should be highlighted, since it does not show stress states, considering that they were not calculated.

In the following, the average of the global displacement related to the composite plate is shown (Fig. 16a), along with the trend of the local acceleration as a function of time (Fig. 16b). In particular, Fig. 16a provides the permanent static deflection experienced by the sample at the end of the impact, while Fig. 16b shows the curve of the absolute maximum acceleration linked to the impact zone.

The remaining other two impact levels were analysed following the procedure mentioned for the 5 and $10 \mathrm{~J}$ cases. Table 5 summarizes the main results obtained, by comparing them with the calculated dent depth for each sample.

It is possible to note how the \% error varies from 8.01 to $21.69 \%$; the values can be considered as reasonable, taking into account the very complex structure of the SCB samples. Interestingly, the lowest error was obtained for the highest impact energy, and vice versa. A possible explanation may be related to the preventive model. Although the seg- mented representative piece of SCB was extrapolated from the sample impacted at $20 \mathrm{~J}$ (Fig. 5c, e), no correlation can be found between them due to the random structure of the plates along the three axes. Since the model demonstrated a good fidelity in terms of maximum degree of uncertainty in the input parameters (which is only linked to the definition of the structural parameters calculated in the numerical model representing the real one, and then assigned to its surrogate), and it produced predictions of the dent depth within a reasonable error tolerance (considering, e.g., the random distribution of the fibers along the three directions which compose the samples under inspection), it can be concluded that the model proposed by the authors can be considered as robust.

\section{NDT Techniques Used}

The techniques used in this work were selected on the basis of the heating modes (point, line and surface) in order to explore the whole set of possible applications, according to [63]. This consideration is valid for the infrared thermography (IRT) method, while the DIC is based on a surface mapping by studying the superficial speckle pattern which reflects the state of health of a component due to possible inner defects and after the delivering of a square pulse. Since the square pulse thermal stimulus is useful in both techniques, a synergistic DIC and IRT experimental setup was conceived, realized and used as explained in the following.

The infrared testing followed an enlargement of the point of view from the point to the surface according to physical and mechanical properties of PBs which do not show a brittle behaviour when subjected to an impact loading. In fact, both the zone of the impact and its surrounding area were in-depth studied initially with a punctual point of view, then passing through a linear point of view before arriving to a surface inspection.

This plan followed considerations based on Table 1 and DIC analysis, which are now linked to thermographic anal- 
yses. Table 1 shows a high value of the MOE parameter. The latter indicates a good elastic behavior of the material during the impact loading. The DIC technique analysed the elastoplastic behaviour of the SCB samples after the impact test. In order to test the behaviour of the samples impacted at 5 and $10 \mathrm{~J}$, the analysis was conducted at first on a region sufficiently far from the impact zone. Since the size of the sample was $50 \times 50 \mathrm{~mm}$, the seed of reference was selected on a radius of $25 \mathrm{~mm}$ starting from the centre of the impact. In order to avoid singularity of behavior in the choice of a single point, the authors thought to repeat the test on additional two points spaced at $120^{\circ}$. The first seed of reference showed high displacement values at the border of the sample, possibly due to the cutting process. The cloud of points corresponding to the analysis of this seed showed low displacement values around it. This behavior is typical of zones not subjected to relevant elastoplastic deformations. Repeating the test on the remaining two points, a similar behaviour was noticed. To check possible differences, a fourth point which coincides with the centre of the impact zone was analysed. Selecting the seed in this position, the displacement at the border of the samples remained very similar to the previous cases. As regards the cloud of points, unlike the previous analyses, a high displacement value was detected. It is shown in Sect. 7 for the sake of brevity. The shape of the cloud of points (resembling a triangle) implies that the area at the centre of the sample suffered a strong elastoplastic deformation. On the later stages of the cooling down phase, the shape of the cloud of points has a less regular shape. For them, however, the absolute value of the displacement is still detectable. From this analysis, it is possible to figure out that the elastoplastic behavior of the material reflects what is indicated in Table 1, while the deformation affected only a small area around the impacts, for which punctual, linear and surface thermographic analyses were needed.

\subsection{Square Pulsed Thermography (SPT) Combined with Digital Image Correlation (DIC)}

A combined inspection between DIC and IRT methods was performed simultaneously through separate devices. Deformation maps (from specklegrams) and raw thermograms required to be re-sampled for correlation purposes. The heating phase $(4 \mathrm{~min})$, as well as the frame rate ( 1 thermogram every $2 \mathrm{~s}$ ) were controlled via a smart acquisition system using a timer (Fig. 17). The lamps with a power equal to $250 \mathrm{~W}$ were installed at a distance of $0.35 \mathrm{~m}$ with respect to the impacted face. The lamps were positioned at $45^{\circ}$ angle. The thermal camera (operating in the longwave infrared spectrum, 7.5-13 $\mu \mathrm{m}$, FLIR S65 HS) and the complementary metal-oxide-semiconductor (CMOS) camera $(22.2 \times 14.8 \mathrm{~mm}$ at 10 megapixels: $5.7 \mu \mathrm{m}$ pixel pitch $)$

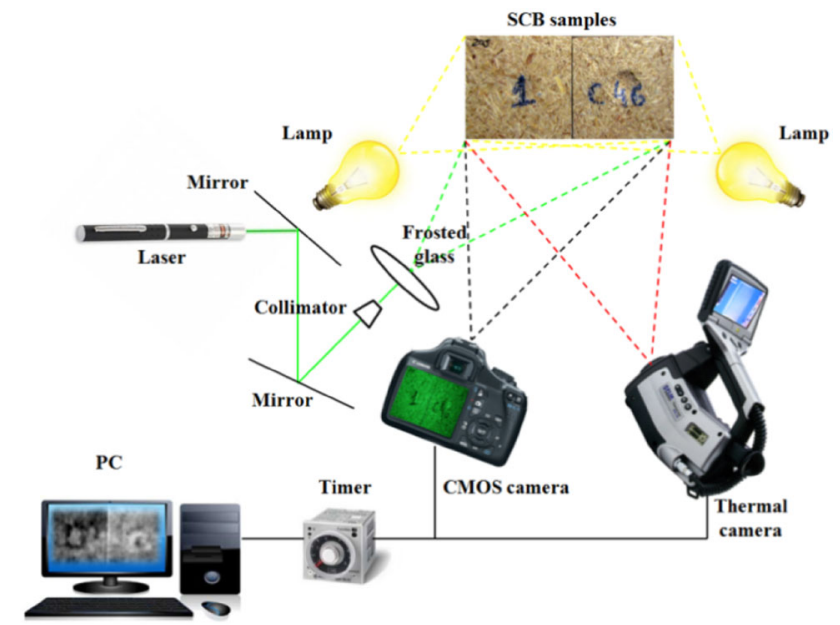

Fig. 17 Synergistic DIC and IRT experimental setup

sensor, were placed at a distance of 0.49 and $0.52 \mathrm{~m}$, respectively.

First, the cold images (i.e., the first specklegram and the first raw thermogram) were recorded at steady-state conditions (ambient temperature $=21.4^{\circ} \mathrm{C}, \mathrm{RH}=45 \%$ ). In addition, also the visible image of the SCB samples was collected. Subsequently, the lamps were switched on together with the registration of the raw thermograms. At the maximum of the heating phase, the lamps were switched off, while the laser $(\lambda=532 \mathrm{~nm}$ as fundamental wavelength, and $250 \mathrm{~mW}$ of power) illuminated the sample one more time, and the registration of the specklegrams began. The use of the laser was fundamental to generate a speckle pattern on the surface under inspection. A speckle pattern is an intensity pattern produced by the mutual interference of a set of wavefronts. This term is commonly used in the experimental mechanics community to describe the pattern of physical speckles on a surface which is useful for measuring, e.g., displacement fields via DIC. In fact, speckle patterns typically occur in diffuse reflections of monochromatic light such as laser light. In order to enlarge the speckle pattern on an extended surface, the use of a frosted glass is considered a clever idea from the scientific community (Fig. 17) [31-33]. The acquisition of the specklegrams and the raw thermograms continued in parallel along the entire cooling down phase $(22 \mathrm{~min})$. At the end of the process, 960 raw thermograms and 330 specklegrams were collected.

In particular, the specklegrams were obtained via an experimental setup including a laser neodymium-doped yttriumaluminium-garnet (Nd:YAG), a holographic table, a camera CANON 40DH: CMOS $(22.2 \times 14.8 \mathrm{~mm}$ at 10 megapixels: $5.7 \mu \mathrm{m}$ pixel pitch) sensor (c. $300-1000 \mathrm{~nm}$ ), an external optics LENS 58-52 Micro Nikkor PC AUTO 1:3, $5 \mathrm{~F}=55 \mathrm{~mm}$ 806055 , a visible filter IDAS ULC-PRO $52 \mathrm{~mm}$ and two lamps having a power of $250 \mathrm{~W}$ each one. The latter stimu- 
lated the sample surfaces with a square pulse from which the SPT method comes from. A square pulse is a non-sinusoidal periodic waveform (which can be represented as an infinite summation of sinusoidal waves), in which the amplitudes alternate at a steady sate frequency between fixed minimum and maximum values, with the same duration at minimum and maximum. The transition between minimum and maximum is instantaneous for an ideal square pulse. SPT is similar to FT (described in Sect. 5.4) but a longer (from a few seconds to several minutes) pulse is used and the surface temperature is monitored during both heating and cooling. Considering the fact that a flash is ideally associated to a thermal stimulus acting for a period of time lasting less than $1 \mathrm{~s}$, the authors preferred to talk about FT and not PT, in order to avoid confusion to the reader since the acronym SPT is also used herein.

\subsection{Laser Spot Thermography (LStT) and Laser Line Thermography (LLT)}

In LStT or LLT, the surface heating at a point a distance away from the laser-spot or laser-line is monitored by a thermal camera. In LLT, the heating provides a measure of the thermal impedance between the heated "spots" generated in a sample constituted by dispersed fibres into a matrix. This impedance increases if a defect-restricting heat flow is present between the extreme points of the line. LStT or LLT are typically performed by moving the laser-spot or the laser-line over the test-piece randomly with a IR surface-reading trained a fixed distance behind the spot or line. In the methods presented here, an IR camera is used to collect full-frame images of the localized heating produced by a laser spot or line on selected points or regions of the SCB samples. The inspection by LStT usually precedes the LLT inspection in order to establish the right direction of the line of heating on a quasi-flat surface.

In the set-up, a mid-wave infrared camera Flir Phoenix [InSb $640 \times 512$ pixels focal plane arrays (FPAs), 3-5 $\mu \mathrm{m}$, Stirling closed cycle cooler] working at a frame rate of $55 \mathrm{fps}$ [noise equivalent temperature difference $(\mathrm{NETD})=25 \mathrm{mK}$ ] was used to record the temperature profiles. A $50 \mathrm{~mm}$ lens was mounted on the infrared camera to identify and characterize the defects. A diode-laser with the wavelength of $805 \mathrm{~nm}$ was used as the heating source. A convex lens was assembled to focus the laser beam, and a waveform generator was used to generate the laser line. A galvanometer scanning mirror with a frequency of $600 \mathrm{~Hz}$ was employed to generate the laser line. The position of the laser line was changed from time to time by modulating the mirror angle. The latter avoids the block of the recording phase of the camera. The laser line was $\sim 10 \mathrm{~mm}$ in length and $3 \mathrm{~mm}$ in width, and its power was set at $0.6 \mathrm{~W}$. The time of interaction with the sample was $0.5 \mathrm{~s}$. The laser spot diameter was $3 \mathrm{~mm}$, and its power was set at $0.22 \mathrm{~W}$.
The same set-up with the installed galvanometer scanning mirror was used for LStT. The position of the laser spot was changed from time to time by modulating the mirror angle. The interaction time with the sample was $0.5 \mathrm{~s}$.

The experimental setups (for LLT and LStT techniques) used in this work can also be found elsewhere [64].

\subsection{Vibrothermography (VT)}

VT, also known as ultrasound thermography or thermosonics, makes use of mechanical waves to directly stimulate defects without heating the surface as in optical methods (e.g., FT and SPT). In VT, ultrasonic waves travel freely through a homogeneous material, whereas an internal defect produces a complex combination of absorption, scattering and dispersion of the waves, whose principal manifestation will be in the form of heat. Heat then travels by conduction to the surface where an IR camera can capture the defect signature. Hence, VT is very useful for the detection of cracks and splitting. Unlike electromagnetic waves, mechanical elastic waves do not propagate in vacuum; on the contrary, they require a medium to travel. They travel faster in solids and liquids than through the air.

There are basically two configurations for VT that can be thought as analogous to optical methods. The first one is the burst VT, and the second one is lock-in VT (or amplitude modulated VT). The ultrasound wave is produced by a transducer made of a stack of piezo elements and concentrated in a titanium horn that acts like a hammer. Hence, the part being inspected should be firmly immobilized (but without being damaged) to avoid cantilever effects, clapping and sliding of the transducer. The transducer horn must be pressed against the sample to improve the coupling transmission of the ultrasound into the specimen. A bad coupling implies a poor ultrasound transmission but more seriously it creates unwanted heat in the vicinity of the ultrasound injection point. When compared to optical/external techniques, the thermal wave travels half the distance in a VT experiment since heat propagation is performed from the defect to the surface, whereas for optical techniques heat travels from the surface to the defects and back to the surface. Hence, VT is very fast, even faster than FT. It is evident that for insulation and elastic materials such as bagasse, the transducer can operate for several seconds without damaging the material itself. Although raw thermograms present sometimes good enough contrast to detect defects, some processing is required most of the time [65].

In the set-up, an ultrasound excitation transducer with a pressure of $200 \mathrm{~Pa}$ was pressed against the sample and a burst of ultrasound waves was delivered to the SCB.

Two $0.2 \mathrm{~Hz}$ lock-in ultrasound excitations $(10 \mathrm{~s})$ were used. The ultrasound excitation position was located on the back face of each sample. The maximum amplitude used was 
$80 \%$. Also in this case, the 'Flir Phoenix' camera was used. The VT system has an ultrasound frequency of $15-25 \mathrm{kHz}$, a modulated pulsed waveform, a minimum modulation frequency equal to $0.1 \mathrm{~Hz}$, a maximum excitation time of $10 \mathrm{~s}$, and an amplitude from 0 to $100 \%$.

Also in this case, interested readers can find the VT experimental setup used in [64].

\subsection{Flash Thermography (FT)}

FT is sometimes called pulsed thermography (PT). Anyway, in this work the authors prefer to use the acronym FT according to $[39,66]$. FT uses optical devices as a source of energy, whose deployment is easier than mechanical excitation. In FT, the sample surface is submitted to a short heat pulse using a high power source such as photographic flashes. After the thermal front comes into contact with the sample's surface, a thermal front travels from the surface through the sample. As time elapses, the surface temperature will decrease uniformly for a piece without internal defects. On the contrary, subsurface discontinuities (e.g., porosity, delaminations, debondings, fiber breakage, inclusions, etc.) can be thought as resistances to heat flow that produce abnormal temperature patterns at the surface that can be detected with an infrared camera. Usually, before delivering the heat some cold images are recorded. A synchronization unit is needed to control the time between the launch of the thermal pulse and the recording phase with the infrared camera. Data is stored as a 3D matrix, where $x$ and $y$ are the spatial coordinates, and $t$ is the time. Temperature decreases approximately as $\mathrm{t}^{1 / 2}$ (at least at early times), as predicted by the 1D solution of the Fourier equation for the propagation of heat by conduction in a semi-infinite isotropic solid that has been stimulated with the well-known Dirac heat pulse.

In this work, one high-power flash (Balcar FX 60), giving $3.2 \mathrm{~kJ}$ for $5 \mathrm{~ms}$ pulse duration, was used as heating source. It was installed in reflection mode. Also in this case, the 'Flir Phoenix' camera was employed in order to record the raw thermograms that were subsequently processed by PCT technique.

\subsection{Line Scanning Thermography (LSgT)}

LSgT deposits heat along a thin line which is swept from edge to edge of the surface under inspection. As explained in the following, an IR camera moves in tandem with the heat source at a set speed, and it is able to capture the thermal profile of the sample after the heat deposition took place. During the scan, the temperature of the region swept by the heat surface increases, whereas the surface temperature of the region in front of the heat application remains constant. In LSgT, heat is deposited in the form of a thin line along the length of the scan. The scan length determines the total length of the thermal image that will be generated using the LSgt protocol. The LSgt technique is able to produce a series of images of the whole area scanned. Each image of the series shows the surface temperature distribution at a given time after heat deposition. The final image or image of the whole area scanned is formed according to Sect. 5.5.1.

In the present case, a Flir microbolometer A65sc $640 \times$ $512,17 \mu \mathrm{m}$ pitch, $7.5-13 \mu \mathrm{m}, 13 \mathrm{~mm}$ focal length with a frame rate of $30 \mathrm{fps}$ and an estimated NETD of $60 \mathrm{mK}$ was used. It was also equipped both with an infrared halogen heater of $1500 \mathrm{~W}$ and length of $30 \mathrm{~cm}$, and with a robot FANUC LR Mate 200iD 7L.

The SCB samples were inspected in motion and the acquired data were reorganized as a pseudo-static sequence (the main information concerning the code will be explained in the Sect.5.5.1), similar to classic static data, in order to perform advanced signal processing like PCT. The thermographic head (consisting of the infrared camera and the energy source) moves along the surface, while the samples are motionless [67]. The thermal history for every line of pixels were precisely tracked by controlling the heating source speed and the rate of data acquisition. The samples were positioned over a table (fixed) while the thermographic head over the robot scanned the impacted surface.

\subsubsection{Pseudo-static Matrix Reconstruction}

A number of parameters need to be selected during a line scanning inspection. Besides the parameters common to static and dynamic configurations [camera's characteristics, field-of-view (FOV), power of the energy source, etc.], additional parameters linked to the relative movement between the inspected part, the energy source and/or the camera, need to be addressed under a dynamic configuration.

The different parameters to be controlled during a line scanning inspection depend on the amount of energy delivered on the sample surface, and the spatiotemporal resolution. For a line scanning system, the amount of energy is strictly connected with the heat source power, the size of the heating time, the scanning speed, and the distance between the source and the surface.

The spatiotemporal resolution is a function of the size of the FPA matrix $\left(p_{x} \times p_{y}\right)$, in which $x$ is the scanning direction and $y$ is the direction perpendicular to the scan; the temporal resolution (after reconstruction) improves at larger $p_{x}$. In addition, it is also a function of the FOV, that strictly depends on the distance between the camera and the impacted surface, the camera's optical characteristics (focal length), the optical distortions, and occlusions. Image rectification and image cropping processes might be needed in the last two points, respectively. 
Finally, an improvement of the spatial resolution in the reconstructed matrix $p_{x^{\prime}}$ happens at higher acquisition rates and for a given scanning speed.

The reconstructed matrix was obtained by following the temporal evolution of every pixel line independently, in such a way that, a given pixel line of the original sequence $P x_{i}(t)$, was recovered frame by frame (through time $t$ ) and reallocated into a new image. For instance, the first pixel line at time $t^{\prime}$, that is $P x_{1}\left(t_{1}\right)$, was rearranged as the first line of the first reconstructed image corresponding to a virtual time $\mathrm{t}_{1}^{\prime}$, that is $P x_{1}^{\prime}\left(t_{1}^{\prime}\right)$. The pixel line at the same position $x_{1}$ but in the following frame (at time $t_{2}$ ), that is $P x_{1}\left(t_{2}\right)$, corresponds to the second line of the reconstructed image at the same virtual time $t_{1}^{\prime}$ (the first frame), that is $P x_{2}^{\prime}\left(t_{1}^{\prime}\right)$, and so on. At the end, the sequence of pixel lines at position $x_{1}$ in the original sequence: $P x_{1}\left(t_{1}\right), \ldots, P x_{1}\left(t_{N}\right)$, is rearranged into a single image representing the first frame at the virtual time $t_{1}^{\prime}: P x_{1}^{\prime}\left(t_{1}^{\prime}\right), \ldots, P x_{2}^{\prime}\left(t_{1}^{\prime}\right)$. The same is true for the rest of the pixel lines in the original sequence:

$$
\begin{aligned}
& P_{x_{1}\left(t_{1}\right), \ldots}, P_{x_{1}\left(t_{N}\right)} \stackrel{\text { reconstructed }}{\longrightarrow} P_{x_{1}^{\prime}\left(t_{1}^{\prime}\right) \ldots}, P_{x_{N}^{\prime}\left(t_{1}^{\prime}\right)}, \\
& P_{x_{2}\left(t_{1}\right) \ldots} P_{x_{2}\left(t_{N}\right)} \stackrel{\text { reconstructed }}{\longrightarrow} P_{x_{1}^{\prime}\left(t_{2}^{\prime}\right) \ldots} P_{x_{N}^{\prime}\left(t_{2}^{\prime}\right)}, \\
& P_{x_{2}\left(t_{1}\right) \ldots} P_{x_{2}\left(t_{N}\right)} \stackrel{\text { reconstructed }}{\longrightarrow} P_{x_{1}^{\prime}\left(t_{2}^{\prime}\right) \ldots} P_{x_{N}^{\prime}\left(t_{2}^{\prime}\right),} \\
& P_{x_{3}\left(t_{1}\right) \ldots} P_{x_{3}\left(t_{N}\right)} \stackrel{\text { reconstructed }}{\longrightarrow} P_{x_{1}^{\prime}\left(t_{3}^{\prime}\right) \ldots} P_{x_{N}^{\prime}\left(t_{3}^{\prime}\right)}, \\
& P_{x_{N}\left(t_{1}\right) \ldots} P_{x_{N}\left(t_{N}\right)} \stackrel{\text { reconstructed }}{\longrightarrow} P_{x_{1}^{\prime}\left(t_{N}^{\prime}\right) \ldots} P_{x_{N}^{\prime}\left(t_{N}^{\prime}\right)} .
\end{aligned}
$$

Since the inspection head is moving over the SCB samples, the object position is continuously shifting from one frame to the next. Unless the camera frame rate is perfectly synchronized with the scanning speed, which is rarely the case, an additional correction on shifting should be performed. This can be done by either using a calibrated target as explained by [42], or by using a shifting correction procedure based on the interpolation between the initial and final positions of a reference pixel. In both cases, it is assumed that the camera and source move at a constant speed.

The observation time $t_{o b s}$ (or time window), i.e., the time during which a given point (line) in the inspected object was observed at a given scanning speed $v_{x}$, can be precisely calculated since the length of the FOV in the scanning direction $X$, is known:

$t_{o b s}=\frac{X}{v_{x}}$.

The virtual acquisition rate of the reconstructed sequence $f_{\text {rate }}^{\prime}$ can then be estimated by knowing the number of pixels being scanned $p_{x}$ during the observation time from $t_{o b s}$ :

$f_{\text {rate }}^{\prime}=\frac{p_{x}}{t_{\text {obs }}}=\frac{1}{\Delta t^{\prime}}$, where $t^{\prime}$ is referred to the virtual time as previously indicated. Equations 17 and 19 were employed to reconstruct the pseudo-static sequence from the dynamic matrix and to determine the observation time and frame rate for every pixel in the new sequence $[68,69]$.

\section{Infrared Image Processing}

In this section, the image processing used with the raw thermographic data are explained in order to introduce the reader to Sect. 8 where the thermographic results will be discussed.

\subsection{Cold Image Subtraction (CIS)}

CIS is intended to decrease the impact of fixed artefacts in thermographic images. These may include the reflections acquired from the surrounding area, such as remaining heating from lamps, the reflection from the camera, which appears in the progress of acquisitions, etc. Because these artefacts do not change in time if the scene recorded in front of the lens does not move, this unwanted effect can decrease its impact on the final result, by subtracting the cold image (or the average of a few images acquired before the starting of the heating up phase) from the whole sequence.

\subsubsection{Principal Component Thermography (PCT)}

PCT, originally proposed by Rajic [44] in 2002, extracts the image features and reduces undesirable signals. It relies on singular value decomposition, which is a tool to extract spatial and temporal data from a matrix in a compact manner by projecting original data onto a system of orthogonal components, known as empirical orthogonal functions (EOFs). The first $\mathrm{EOF}$ will provide the most important characteristic variability of the data; the second EOF will provide the second most important variability, and so on. Original data can often be adequately represented with only a few EOFs. Usually, an infrared sequence of 1000 images can be replaced by 10 or less EOFs.

\section{Main Information Regarding the 2D Correlation Test Procedure, Experimental Results and Discussion}

Ncorr is an open source 2D DIC Matlab ${ }^{\circledR}$ program. It has an accessible and intuitive graphical user interface (GUI), uses many novel DIC algorithms, is fully contained within the Matlab ${ }^{\circledR}$ environment, and contains plotting tools for figure creations [35]. The analysis is conducted using C++/MEX. The aim of the analysis is the detection of the gradient of 
the small deformations that are generated during the cooling down phase after the application of a thermal load.

DIC is based on recording speckle patterns before and after the application of load. For insulating materials, such as bagasse, the speckle patterns acquired during the cooling down phase take on a great importance, as well as the cold specklegram. This is one of the simplest method in which a laser-lit diffuse surface is recorded at two different states of stress. DIC allows to measure in-plane displacements and derivatives of deformation. All the deformed images show a different random dot pattern relative to the initial nondeformed reference image. Using Ncorr, these differences between patterns can be calculated by correlating all the pixels [or a region of interest (ROI) of pixels] of the reference image and any deformed image; at the end of the process, e.g., a displacement map can be created.

First, a specklegram at ambient temperature was recorded; subsequently, the pair of samples (5 and 10-20 and 30 J) was illuminated for $4 \mathrm{~min}$ and a second specklegram was acquired at the end of the heating phase. Finally, a series of specklegrams were recorded during the cooling down phase with a frame rate equal to 1 specklegram every $4 \mathrm{~s}$. Now the image processing can be conducted. The set reference image is the undisturbed specklegram. It was correlated with the specklegram recorded at the fourth minute, as well as with the following four specklegrams equi-spaced of $330 \mathrm{~s}$ inherent to the cooling down phase lasting $22 \mathrm{~min}$. After this step, the ROI were selected and the DIC technique was carried out. Each ROI analysed coincides with the $x-y$ surface of each sample, as shown in Figs. 18 and 19. This choice was made, because: (a) the surface of the impacted sample is not too large $(50 \times 50 \mathrm{~mm})$; this is not in contrast with the resolution limits of the program and the distance sample-camera, and (b) concerning the numerical point-of-view, the possibility of having a large set of points was not compromised by the impacts on which the correlation and its respective coefficient are calculated. This tends to stabilize the numerical method, by simultaneously reducing the minimum number of iterations. This is due to the greater regularity of the function in the neighbourhood of the impacted area.

Subsequently, the DIC parameters were selected [36]. Among the parameters to be chosen, there are: (a) subset option, (b) multithreading option, (c) high strain analysis and (d) discontinuous analysis. The first allows the choice of the size of the subsets, as well as the distance between them. The dimension indicating the spacing should be carefully chosen to limit the computational cost. Initially, the code sets the default values in relation to the size of the input images. In our case, they have been appropriately modified to obtain the maximum performance, by also avoiding the smoothing effect which is typical of the very wide range. In practice, the smallest subset should be selected, by avoiding-in this way-the noise as much as possible. The second allows the user to choose the number of cores in order to parallelize the calculation and, therefore, speed it up. In our case, four cores were selected, while the third option was not used herein. Indeed, it is activated only in the study of highly deformable materials where it is necessary to choose several reference images during the evolution of the deformation state. The last option was not used since it is generally applied during the on-line deformation studies producing large cracks. It allows to highlight the deformation at the crack tips.

The selection of the DIC parameters avoids numerical problems linked to the processing of the correlation phase of the specklegrams. The select region and the seed placement are useful commands of the DIC analysis. The first one allows the selection of the ROI on which the analysis will be conducted, while the second one permits to study some points of interest located into the ROI in order to monitor them in terms of strain and stress. If different points are chosen, it is possible to compare their mechanical characteristics when subjected to a thermal stress. Generally, the latter type of analysis is focused on areas around a crack.

Taking into account the previously mentioned benefits, the iterative solver linked to the subset option was adopted in the present case. In addition, the seed placement was chosen. This allows the starting point of the analysis to be identified. It also allows the parallelization of the individual partitions of the ROI starting from the indicated point of interest. The stress analysis is therefore accomplished by considering the continuum hypothesis, i.e., the Coleman-Noll's hypothesis. Also Euler's tensor or Euler-Almansi's tensor can be selected. They were used during the image processing for consistency with the numerical simulation explained above.

The analysis of deformation in continuous mechanics starts with the Cauchy-Green tensor. The idea comes from the definition of the variation of a line length of a generic element which follows a deformation. In order to evaluate the variation of configuration before and after the deformation, the variation in the geometry experienced by the line element is expressed with a quadratic form. Developing from a deformed configuration, it is possible to connect the latter with an undeformed configuration using a symmetrical double tensor. Through the tensorial mathematical development, it is possible to notice that this tensor is symmetrical and the quadratic form linked with it is defined as positive. Therefore, the tensor can be thought as two separate tensors (left and right) which are known as Cauchy-Green tensors. After transformation procedures, these tensors can be further divided via the polar decomposition theorem. This theorem allows to decompose the kinematic of deformation by three additional tensors, named: right stretch tensor, left stretch tensor and rotation tensor. The splitting into these tensors helps the final goal to be reached, i.e., the tensor model. The tensors of Green-Lagrange and Euler-Almansi are linked to the right tensor and the reverse of the left ten- 
(a)

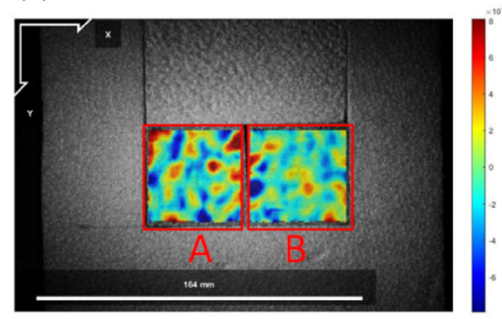

(b)

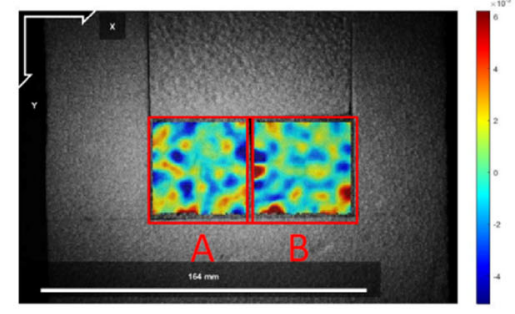

(c)

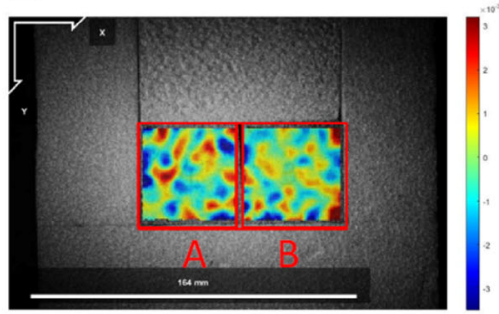

(d)

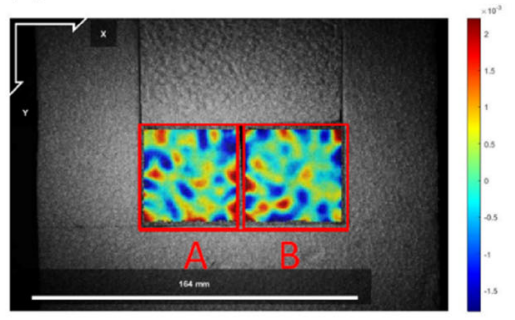

Fig. 18 a Trend tensor according to Euler-Almansi: a correlation between the specklegram at the steady-state condition and the instant at the end of heating, $\mathbf{b}$ correlation between the specklegram at the steadystate condition and at $330 \mathrm{~s}$ after the starting of the cooling down phase, c correlation between the specklegram at the steady-state condition

sor of Cauchy-Green, respectively. The tensor strain (i.e., the Green-Lagrange strain tensor) is so-called because it characterizes the deformation analysis thanks to a material approach (i.e., a Lagrangian approach), while the Almansi tensor (i.e., the Euler-Almansi strain tensor) is a strain tensor characterized by a deformation analysis with a spatial approach (i.e., a Eulerian approach).

The results from the correlation technique via tensor images of Lagrange, Euler-Almansi and the overview of the strain are shown in Figs. 18, 19 and 20, respectively.

The samples impacted at 5 and $10 \mathrm{~J}$, named $\mathbf{A}$ and $\mathbf{B}$, respectively (see Figs. 18, 19, 20 for reference), were analysed at the same time (Fig. 17) applying a heating focused on both sample surfaces, and a frame rate equal to the case 20-30 J, for which the tensor images are not shown here although the Green-Lagrange trend is plotted in the following. Looking at both the Euler-Almansi and Lagrange results it is possible to notice a patchy distribution. This behaviour may be attributable to the structure of the composite fibres (mat) that does not allow (without a punctual analysis in the course of time) the highlighting of preferential directions. As it can be noted, the distribution of the red spots is higher at the border of the samples. It can be linked to the cutting process (and not to the impact loading) which increases the temperature on those areas, thus affecting the properties of the matrix. In Fig. 20, the strain was analysed as a dispersion of the points of the ROI. The explanation of the displacement values has already been provided at the initial stage of Sect. 5. The zero point was selected on the basis of additional (e)

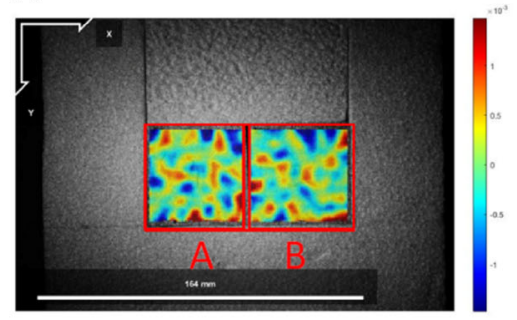

and at $660 \mathrm{~s}$ after the starting of the cooling down phase, $\mathbf{d}$ correlation between the specklegram at the steady-state condition and at $990 \mathrm{~s}$ after the starting of the cooling down phase, and e correlation between the specklegram at the steady-state condition and at $1320 \mathrm{~s}$ after the starting of the cooling down phase

analyses conducted around the impact zones, and excluding the border of the samples taking into account the possible presence of resin-poor areas due to the cutting process, and the usual boundary effects. The zero point (marked by green points) for each sample is highlighted by the seed. Concerning this image processing, the greatest interest is focused on the dispersion of the points under analysis observable in the displacement diagram. The points analysed are depicted by circles (i.e., the cloud of points). It is evident a distribution condensed between 0 and $0.1 \mathrm{~mm}$. Since the trend can be assimilated and discussed together, a consistency behaviour between the samples subjected to a thermal loading is clear. In Fig. 21, the trend inherent to the seeds is shown.

Observing the first strain trend (Fig. 21a) according to Green-Lagrange, it is possible to notice a constant reduction of the strain at the end of the thermal loading up to the second image; subsequently, the evolution tends to be more stable. It should be noted that between the images there is a time interval equal to $330 \mathrm{~s}$. This implies that, during the first time interval, the cooling rate is more pronounced. The analysis is in perfect agreement with the test conditions. Also the absolute position of the curves replicates the expected response after a known thermal load distributed on samples impacted with different energies.

In contrast to Fig. 21a, the case 20-30 J (Fig. 21b) shows a more pronounced state of permanent deformation, therefore, the higher local deformation of the material modifies the strain behaviour in the course of time. 
(a)

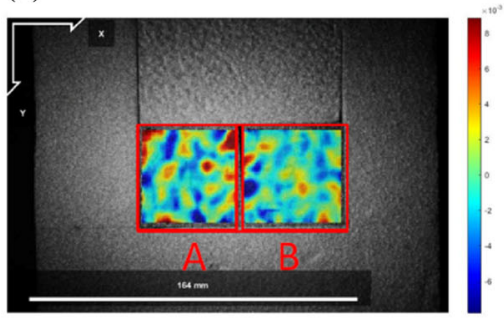

(d)

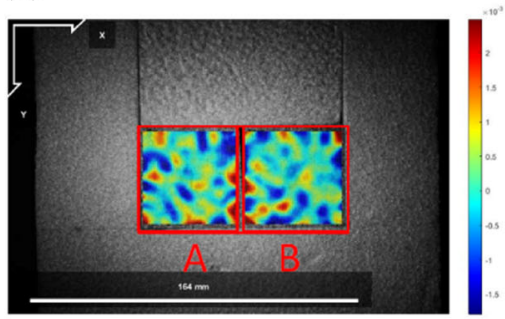

Fig. 19 a Trend tensor according to Lagrange: a correlation between the specklegram at the steady-state condition and the instant at the end of heating, b correlation between the specklegram at the steady-state condition and at $330 \mathrm{~s}$ after the starting of the cooling down phase, c correlation between the specklegram at the steady-state condition (b)

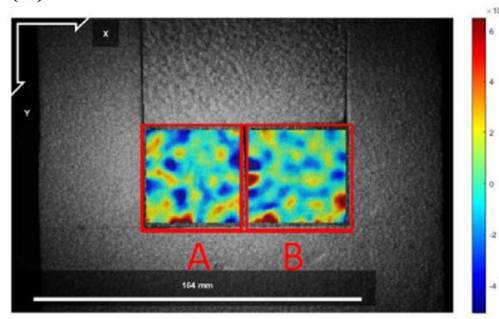

(c)

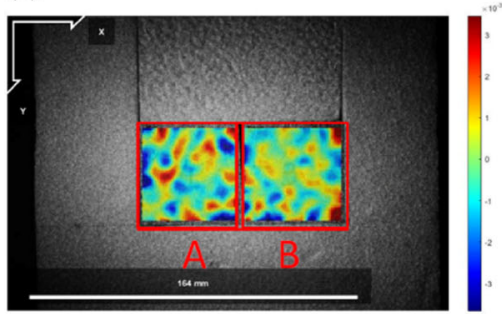

(a)

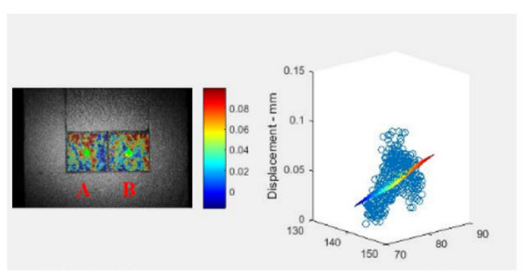

(d)

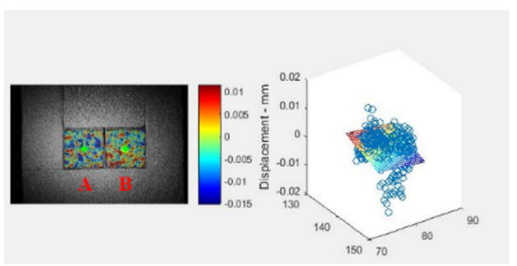

Fig. 20 a Trend of the strain tensor: a correlation between the specklegram at the steady-state condition and the instant at the end of heating, $\mathbf{b}$ correlation between the specklegram at the steady-state condition and at $330 \mathrm{~s}$ after the starting of the cooling down phase, $\mathbf{c}$ correlation between the specklegram at the steady-state condition and at $660 \mathrm{~s}$ after the start-

\section{Thermographic Results and Discussion}

Both long-wave and mid-wave thermal cameras were used in order to inspect the samples. Regarding the sample impacted with $5 \mathrm{~J}$, first the LStT technique was used (Fig. 22a). The heat diffusion in the course of time of the spot region revealed a horizontal direction highlighted by the arrow. The spot was

(b) (e)

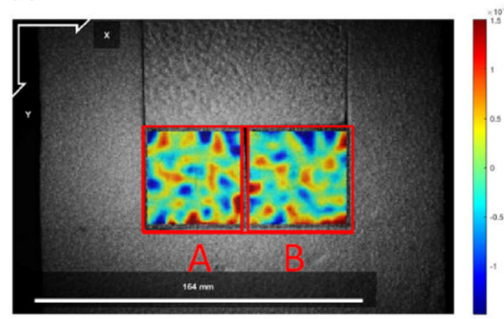

and at 660 s after the starting of the cooling down phase, $\mathbf{d}$ correlation between the specklegram at the steady-state condition and at $990 \mathrm{~s}$ after the starting of the cooling down phase, and e correlation between the specklegram at the steady-state condition and at $1320 \mathrm{~s}$ after the starting of the cooling down phase

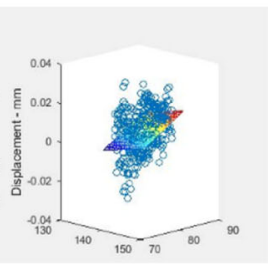

(e)

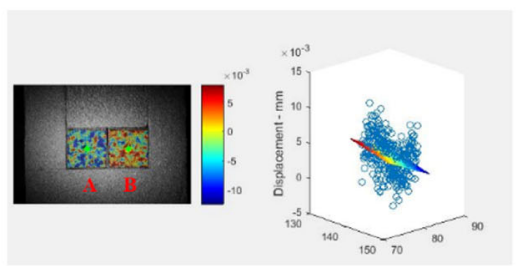

ing of the cooling down phase, $\mathbf{d}$ correlation between the specklegram at the steady-state condition and at $990 \mathrm{~s}$ after the starting of the cooling down phase, and e correlation between the specklegram at the steadystate condition and at $1320 \mathrm{~s}$ after the starting of the cooling down phase

located at the center of the impact which is slightly evident to the naked eye (Fig. 5a).

Its behavior inspired the authors to once again inspect the impact zone through a line (Fig. 22b) instead of a spot. Two satellite defects were detected on the left and right border of the impact. In particular, the defects on the right appear more pronounced. The presence was also confirmed by using FT 
(a)

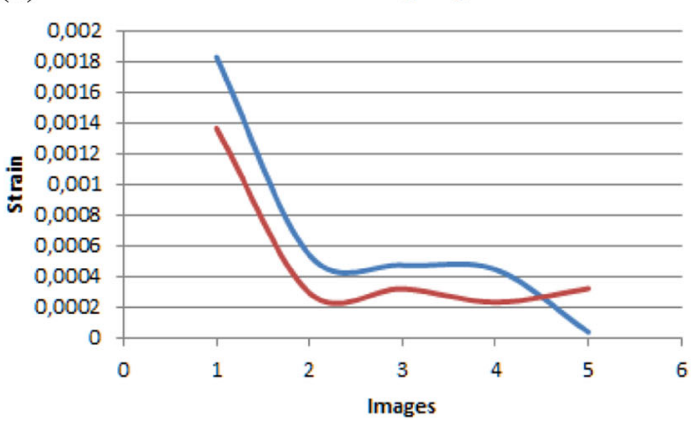

(b)

Green - Lagrange $E_{X Y}$

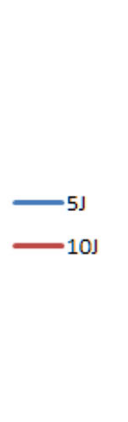

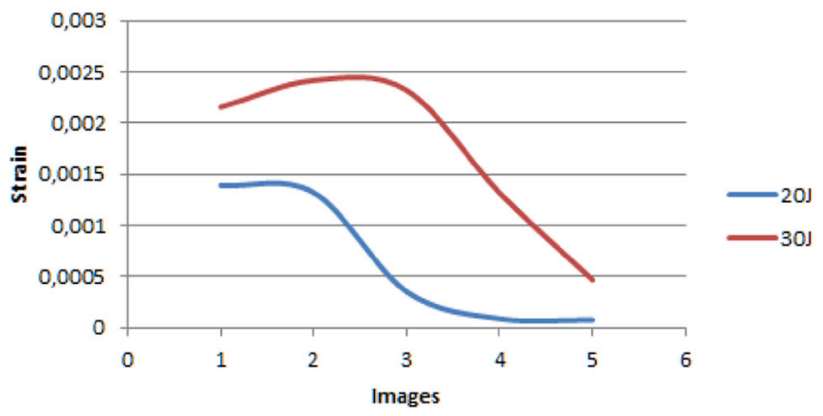

Fig. 21 Comparison among the Green-Lagrange trends: a 5 and $10 \mathrm{~J}$, and b 20 and $30 \mathrm{~J}$

(a)

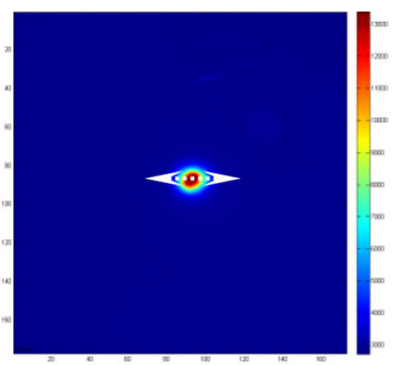

(d)

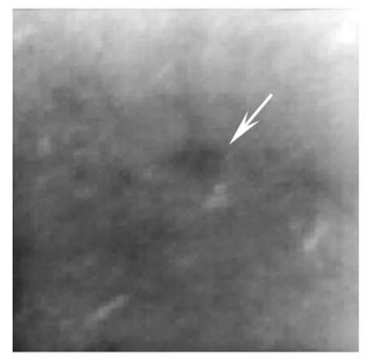

(b)

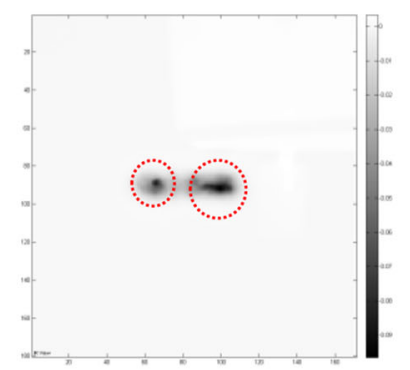

(e)

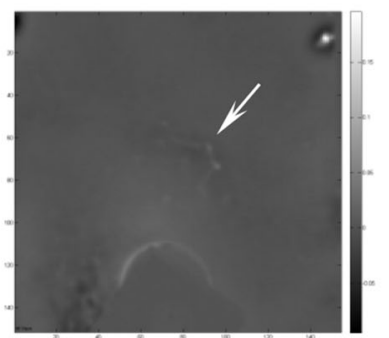

(c)

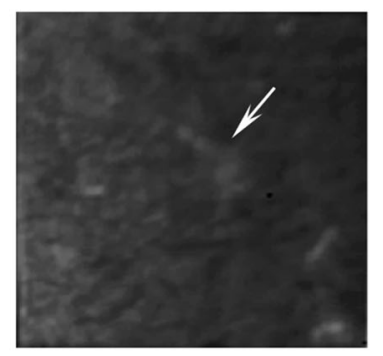

(f)

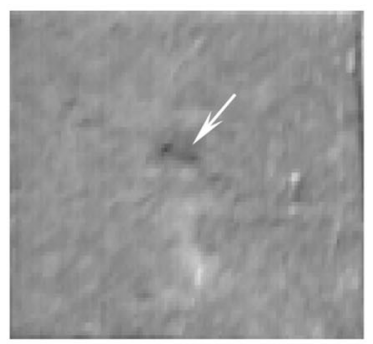

Fig. 22 SCB sample impacted with 5J: a LStT result using a power of the heat source of $0.22 \mathrm{~W}$ and a time of sample-laser interaction of $0.5 \mathrm{~s}$. The image is a raw thermogram acquired at $1.5 \mathrm{~s}$ during the cooling down phase, $\mathbf{b}$ LLT result using a power of the heat source of $0.6 \mathrm{~W}$ and a time of sample-laser interaction of $0.5 \mathrm{~s}$. The image refers to the PCT technique $\left(\mathrm{EOF}_{2}\right)$, $\mathbf{c}$ raw thermogram acquired after a flash heating lasted $4 \mathrm{~ms}$ (the first thermogram of the cooling down phase), $\mathbf{d}$ the image refers to the PCT technique $\left(\mathrm{EOF}_{2}\right)$ acquired after a square pulse provided by halogen lamps, e the image refers to the VT technique using a frequency of $0.2 \mathrm{~Hz}$ and a time of vibration of $10 \mathrm{~s}$. It is the $\mathrm{EOF}_{4}$ inherent to the PCT technique, and $\mathbf{f}$ the image refers to the LSgT technique using a linear lamp as heating source (1500 W IR heater) and a semi-static reconstruction of the thermograms. It is the $\mathrm{EOF}_{5}$ inherent to the PCT technique. The line direction used for heating is indicated with a red arrow in Fig. 5a
(Fig. 22c), a long pulse (Fig. 22d), VT (Fig. 22e) and LSgT (using a linear lamp, Fig. 22f) techniques. The heat generated by the laser spot, therefore, moves from the source (impacted zone) to the heat accumulator, i.e., a possible detachment.

The same methodology was also used for the $10 \mathrm{~J}$ case. The horizontal direction of the diffusion process after the launching of the laser spot appears to be the most evident thanks to the use of the PCT technique (Fig. 23a).

For consistency with the previous case analysed, the LLT technique was applied along the horizontal direction because the higher diffusion was detected along that direction. An arrow added to Fig. 23a indicates the diffusion line.

Nevertheless, neither the LLT (Fig. 23b) nor the FT (Fig. 23c) techniques revealed noticeable sub-superficial thermal imprints. In order to investigate the sample in more detail, SPT (Fig. 23d), VT (Fig. 23e), and the LSgT (using a linear lamp as thermal source) techniques were applied. In all three cases a detachment can be observed near to the impact zone. It is indicated by an arrow. Maybe the behaviour of the laser spot impacting the front face of the SCB sample is 
(a)

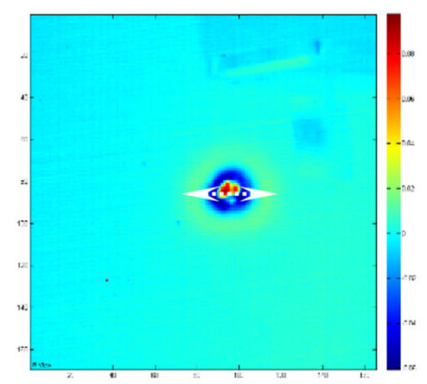

(d)

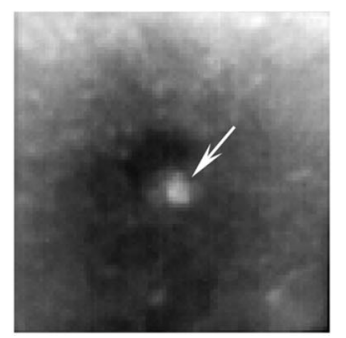

(b)

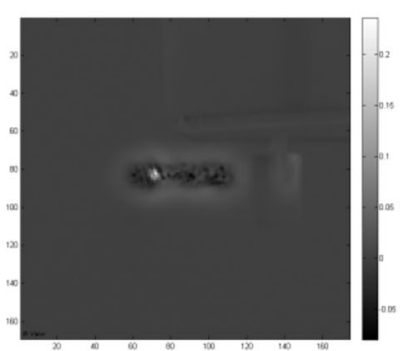

(e)

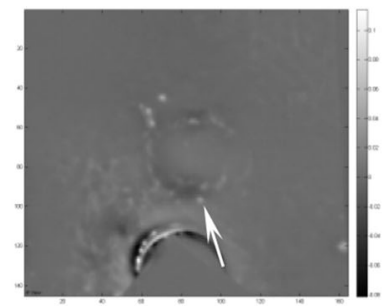

(c)

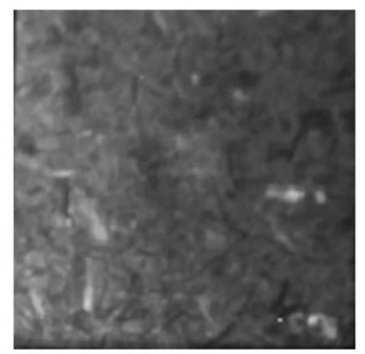

(f)

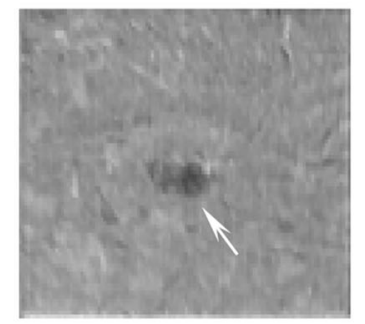

Fig. 23 SCB sample impacted with 10 J: a LStT result using a power of the heat source of $0.22 \mathrm{~W}$ and a time of sample-laser interaction of $0.5 \mathrm{~s}$. The image corresponds to the $\mathrm{EOF}_{3}$ that is inherent to the PCT technique, b LLT result using a power of the heat source of $0.6 \mathrm{~W}$ and a time of sample-laser interaction of $0.5 \mathrm{~s}$. The image refers to the PCT technique $\left(\mathrm{EOF}_{5}\right)$, c raw thermogram acquired after a flash heating lasted $4 \mathrm{~ms}$ (the first thermogram of the cooling down phase), $\mathbf{d}$ the image refers to the PCT technique $\left(\mathrm{EOF}_{2}\right)$ acquired after a square pulse provided by halogen lamps, e the image refers to the VT technique using a frequency of $0.2 \mathrm{~Hz}$ and a time of vibration of $10 \mathrm{~s}$. It is the $\mathrm{EOF}_{6}$ inherent to the PCT technique, and $\mathbf{f}$ the image refers to the LSgT technique using a linear lamp as heating source (1500 W IR heater) and a semi-static reconstruction of the thermograms. It is the $\mathrm{EOF}_{5}$ inherent to the PCT technique. The line direction used for heating is indicated with a red arrow in Fig. 5b affected by micro-cracks arose after the impact which act, again, as heat accumulators.

The sample impacted with $20 \mathrm{~J}$ shows a trend of the laser spot (Fig. 24a) centred into the impacted zone to diffuse itself more on the right side with a slight declivity. Taking into account the previous experiences, it is possible to assume that on this direction a sub-superficial defect is present. In this regard, no clear conclusion can be made after the application of the LLT technique (Fig. 24b). Instead, a full-field image obtained from FT (Fig. 24c), long pulse (Fig. 24d), VT (Fig. 24e) and LSgT using a linear lamp as thermal source (Fig. 24f), after the image processing clarifies that a detachment acting like a heat accumulator is present in that zone. It is also highlighted by a red arrow where it is detectable.

Concerning the sample impacted with $30 \mathrm{~J}$, a series of data obtained using the LStT technique were initially observed. Among these, the behaviour of the spot shown in Fig. 25a attracted the attention of the authors. This point is located near to the impact (Fig. 5d) and no defect is visible to the naked eye.

Starting from this point-of-view, data were also processed by PCT after a short pulse along a line generated by a laser
(Fig. 25b). The position of the line was selected by considering both the LStT result, the FT result (Fig. 25c, note an area at higher temperature) and a previous thermographic analysis based on a square pulse delivered by halogen lamps (Fig. 25d). The evidence of a sub-superficial discontinuity was provided in all cases. At this point, it is possible to affirm that the direction of the diffusion process after the administration of the laser spot (Fig. 25a) follows a $45^{\circ}$ angle due to a sub-superficial characteristic. This behaviour may be linked to the Aindow's criterion [70], i.e., the heat propagates faster in the longitudinal direction of the fibre, on the surface of the fibre reinforced laminates. The result can be considered as a corroboration of the theory for a different material.

However, additional satellite defects are present in Fig. 25d (see the upper part of the impacted area), which were also confirmed by VT (Fig. 25e) and LSgT (using a linear lamp as thermal source, Fig. 25f) techniques. Readers should note that also in the VT result, the horizontal dotted line crosses a defect only on the left part of the impact, similarly to the observation made during the application of the SPT method.

The dark spot detectable in Fig. 25b, may be attributable to the small concavity whereby the left extremity of the impact 
(a)

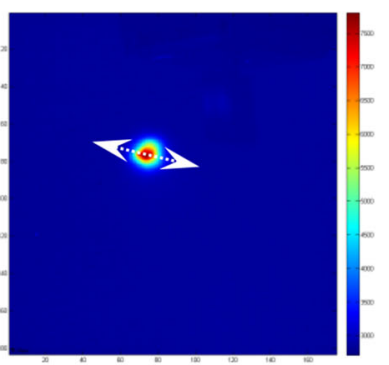

(d)

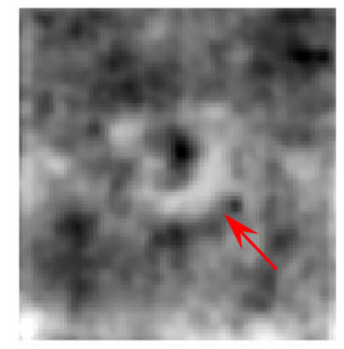

(b)

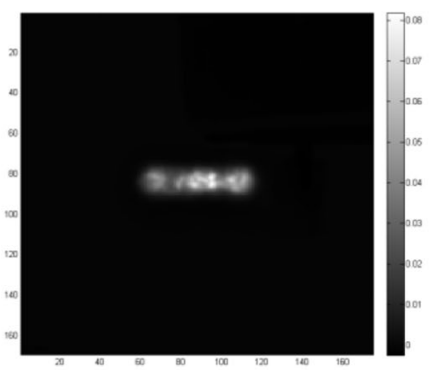

(e)

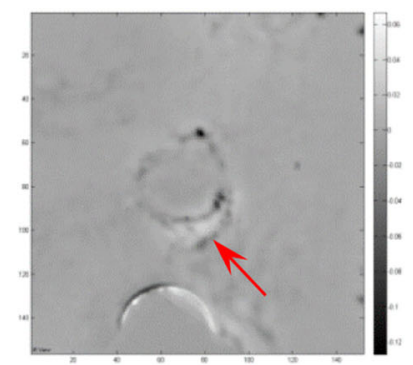

(c)

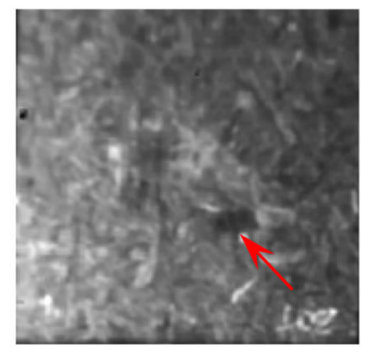

(f)

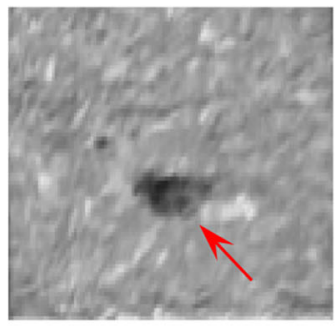

Fig. 24 SCB sample impacted with $20 \mathrm{~J}$ : a LStT result using a power of the heat source of $0.22 \mathrm{~W}$ and a time of sample-laser interaction of $0.5 \mathrm{~s}$. The image is a raw thermogram acquired at $1.5 \mathrm{~s}$ during the cooling down phase, $\mathbf{b}$ LLT result using a power of the heat source of $0.6 \mathrm{~W}$ and a time of sample-laser interaction of $0.5 \mathrm{~s}$. The image refers to the PCT technique $\left(\mathrm{EOF}_{2}\right)$, $\mathbf{c}$ raw thermogram acquired after a flash heating lasted $4 \mathrm{~ms}$ (the first thermogram of the cooling down phase), $\mathbf{d}$ the image refers to the PCT technique $\left(\mathrm{EOF}_{5}\right)$ acquired after a square pulse provided by halogen lamps, e the image refers to the VT technique using a frequency of $0.2 \mathrm{~Hz}$ and a time of vibration of $10 \mathrm{~s}$. It is the $\mathrm{EOF}_{5}$ inherent to the PCT technique, and $\mathbf{f}$ the image refers to the LSgT technique using a linear lamp as heating source ( $1500 \mathrm{~W}$ IR heater) and a semi-static reconstruction of the thermograms. It is the $\mathrm{EOF}_{5}$ inherent to the PCT technique. The line direction used for heating is indicated with a red arrow in Fig. 5c ends (Fig. 25g). One can also observe the difference between the left and the right terminal parts of the typical profile, which are surrounded by dotted red ovals. It is possible to assume that the heat remains trapped in this small area due to debonding between fibers and matrix. The right part, however, is a convexity and not a concavity, and therefore free of defects. In this case, the heat differently propagates itself along the three axes, therefore, sub-superficial defects are not detectable.

Finally, the LLT and VT were also applied on the rear side of the sample in order to discover possible damage due to the highest energy of the impact. A visible image acquired in raking light (i.e., the illumination of objects from a light source at an oblique angle or almost parallel to the surface which provides information on the surface topography) of the rear side which excludes any possible damage detectable to the naked eye is shown in Fig. 25h. Four different positions were analyzed using the LLT technique.

The results are intriguing also by using the simplest image processing technique, i.e., the subtraction of the cold image from the total sequence. Indeed, Fig. 25i shows the presence of a detachment in which the left border is marked by an arrow, while Fig. $25 \mathrm{~m}$ illustrates a crack pointed out by another arrow. It is evident how, in the first case, the heat remained trapped only on the right part of the line generated by a laser, while in the second case a crack interrupted the diffusion of the heating along the $z$ direction. Both defects were retrieved by VT (Fig. 251) via PCT. Finally, the impacted area was also inspected from the rear side. The PCT result reported in Fig. 25n shows a small damage. Indeed, the most important damage is located in the area surrounding the impact. For this reason, the second position (Fig. 25h) was also inspected from another direction. The result inherent to Fig. 25o confirms the presence of the crack (Fig. 25m) as well as an additional crack. Both are indicated by arrows.

\section{Conclusions}

In the paper, the post-impact evaluation of samples composed of homogeneous PBs of SCB was performed. Specifically, thermographic, optical and mechanical techniques were used. A numerical simulation in Comsol Multiphysics ${ }^{\circledR}$ anticipated the mechanical analyses, as well as the impact 
damages linked to low velocity impacts from 5 to $30 \mathrm{~J}$. A good correlation between the simulation and the real dent depth $[71,72]$ caused in the samples was observed. Numerically speaking, the approach was optimized ad hoc for the present case-study; indeed, the von Mises's method was readapted. The \% errors between the dent depth experimentally calculated and the dent depth numerically calculated range from 8.01 to $21.69 \%$. In particular, the error increases as the impact loading decreases. Due to the complexity of the structures under analysis, the numerical evaluation of the satellite defects around the impacts cannot be revealed after the simulation procedures. Therefore, one of the main pros of the model is undoubtedly the estimation of the dent depth, while one of the main cons the inability to predict the appearing of (a)

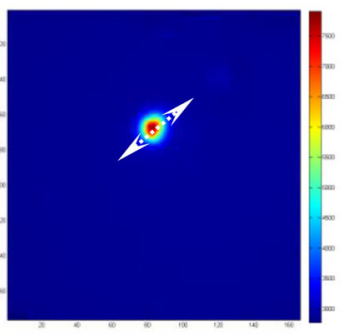

(d)

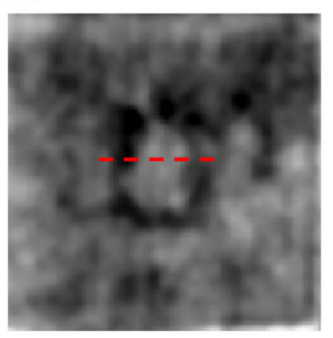

(b)

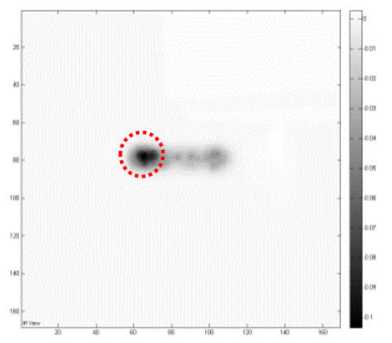

(e)

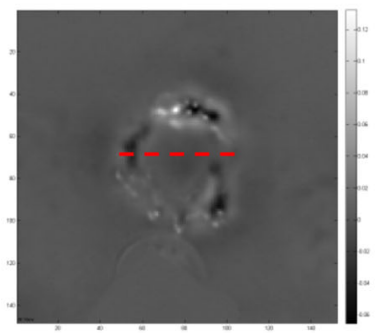

(c)

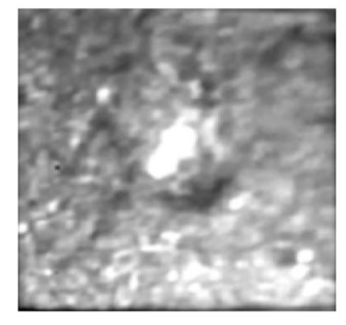

(f)

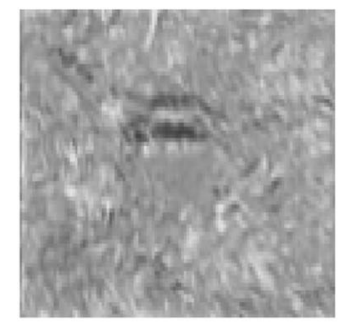

(g)

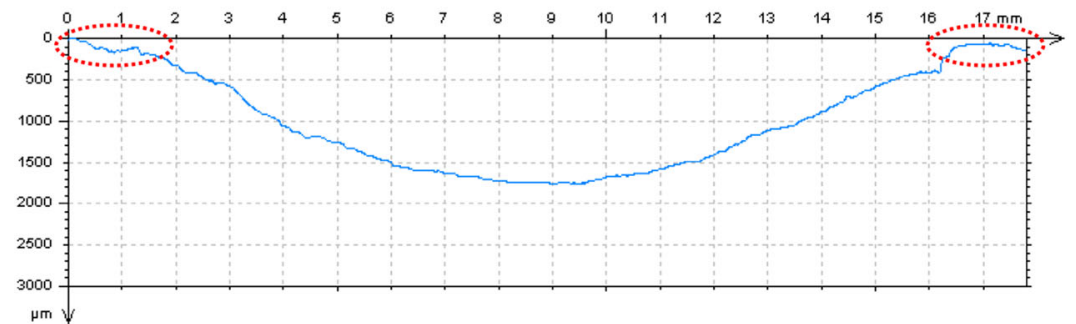

(h)

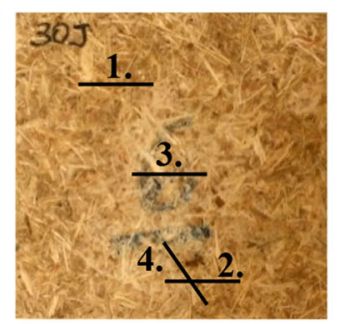

Fig. 25 SCB sample impacted with $30 \mathrm{~J}$ (front side): a LStT result using a power of the heat source of $0.22 \mathrm{~W}$ and a time of sample-laser interaction of $0.5 \mathrm{~s}$. The image is a raw thermogram acquired at $1.5 \mathrm{~s}$ during the cooling down phase, $\mathbf{b}$ LLT result using a power of the heat source of $0.6 \mathrm{~W}$ and a time of sample-laser interaction of $0.5 \mathrm{~s}$. The image refers to the PCT technique $\left(\mathrm{EOF}_{2}\right)$, $\mathbf{c}$ raw thermogram acquired after a flash heating lasted $4 \mathrm{~ms}$ (the first thermogram of the cooling down phase), $\mathbf{d}$ the image refers to the PCT technique $\left(\mathrm{EOF}_{5}\right)$ acquired after a square pulse provided by halogen lamps, e the image refers to the VT technique using a frequency of $0.2 \mathrm{~Hz}$ and a time of vibration of $10 \mathrm{~s}$. It is the $\mathrm{EOF}_{6}$ inherent to the PCT technique, $\mathbf{f}$ the image refers to the LSgT technique using a linear lamp as heating source (1500 W IR heater) and a semi-static reconstruction of the thermograms. It is the $\mathrm{EOF}_{5}$ inherent to the PCT technique; the line direction used for heating is indicated with a red arrow in Fig. 5d, $\mathbf{g}$ typical residual indentation profile; SCB sample impacted with $30 \mathrm{~J}$ (rear side): $\mathbf{h}$ visible image of the rear side with marked the positions of the LLT acquisitions, $\mathbf{i}$ LLT result using a power of the heat source of $0.6 \mathrm{~W}$ and a time of sample-laser interaction of $0.5 \mathrm{~s}$. The image refers to the cooling down phase (acquired after $1.5 \mathrm{~s}$ from its starting and by subtracting the cold image); it is linked to the first position signalled in $\mathbf{h}, \mathbf{l}$ the image refers to the VT technique using a frequency of $0.2 \mathrm{~Hz}$ and a time of vibration of $10 \mathrm{~s}$. It is the $\mathrm{EOF}_{9}$ inherent to the PCT technique, $\mathbf{m}$ LLT result using a power of the heat source of $0.6 \mathrm{~W}$ and a time of sample-laser interaction of $0.5 \mathrm{~s}$. The image refers to the cooling down phase (acquired after $1.5 \mathrm{~s}$ from its starting and by subtracting the cold image); it is linked to the second position signalled in $\mathbf{h}, \mathbf{n}$ LLT result using a power of the heat source of $0.6 \mathrm{~W}$ and a time of sample-laser interaction of $0.5 \mathrm{~s}$. The image refers to the PCT technique $\left(\mathrm{EOF}_{2}\right)$; it is linked to the third position signalled in $\mathbf{h}$, and $\mathbf{o}$ LLT result using a power of the heat source of $0.6 \mathrm{~W}$ and a time of sample-laser interaction of $0.5 \mathrm{~s}$. The image refers to the cooling down phase (acquired after $1.5 \mathrm{~s}$ from its starting and by subtracting the cold image); it is linked to the fourth position signalled in $\mathbf{h}$ 
(i)

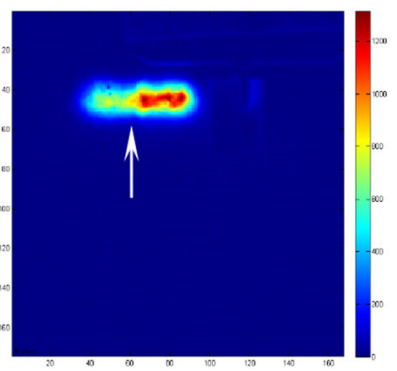

(n)

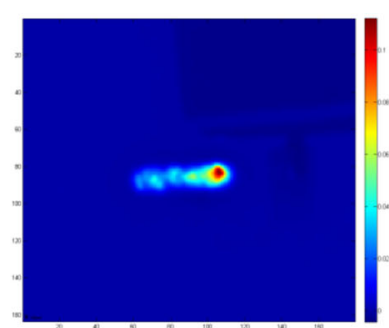

(I)

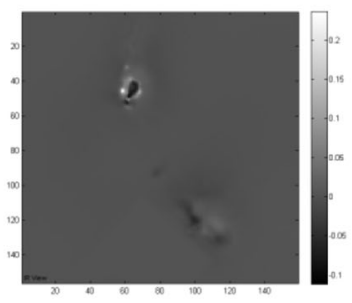

(m)

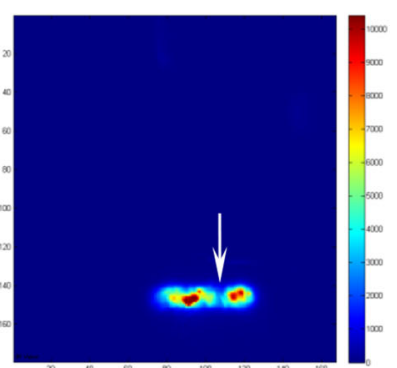

(o)

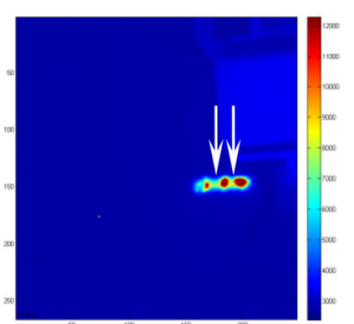

Fig. 25 continued

cracks, detachments, and so on, due to the different impact loadings. Indeed, the experimental analysis follows (i.e., not precedes) the numerical calculations, as explained in the title.

Two different thermal cameras were used since this work is based on a long-time collaboration among eight university departments, located in six different countries. To demonstrate the pros and cons of the different sensors used both in size and in the working spectral range, the samples were moved in two different laboratories. The cameras can be considered equivalent in terms of temperature sensitivity, although the bigger sensor is more suitable to work under laser conditions by considering the slight thermal nuances to be detected. Since the quantitative evaluation of the defect shapes and depths falls outside the purpose of this work, the different measurement accuracy between the cameras was not a concern of the authors. Indeed, it tends to retrieve the positions of the defects via a combined qualitative approach.

To the best of our knowledge, neither optical techniques nor thermographic techniques have been used in the past in order to study sub-superficial characteristics in this type of material. The work shows that, when optical and thermographic techniques are combined, interesting details can be observed, such as the presence of satellite defects which was linked-by means of comparison-to a concave area detected by profilometry. For example, the VT technique confirmed the assumptions raised during the use of additional NDT techniques [73-75]. In addition, the VT and LLT techniques were able to identify cracks and detachments also on the rear side of the sample impacted with $30 \mathrm{~J}$. FT was also useful in detecting sub-superficial features, although the use of a long square pulse could be considered more suitable taking into account the thermal characteristics of the ecofriendly composite under inspection.

On the one hand, LStT allowed the understanding of the directions of particular fibers having a width on the $x-y$ plane suitable for inspection using the width of the laser. On the other hand, the newest LSgT technique combined with a robot provided interesting results after a pre-processing of the raw data by a semi-static algorithm and a post-processing by PCT.

In a future work, the relationship between the real thermographic results and thermographic simulations will be deepened in order to attempt to predict the best method for image processing [76]. Finally, Terahertz $(\mathrm{THz})$ inspection will be applied on the same samples in order to understand its penetrating capacity in this innovative material [77].

Acknowledgements The research leading to these results has received funding from The Research Fund: Flanders FWO Travel Grant V4.010.16N and the University of Antwerp (Belgium). In addition, this study was supported by Russian Foundation Grant \#17-19-01047 and in part by Tomsk Polytechnic University Competitiveness Enhancement Program Grant. Finally, the authors want to thank both the Canada Research Chair in Multipolar Infrared Vision (MIVIM) and the FAPESP-Brazil (Proc. 2012/13881-2 and 2013/1985-8) for supporting this research.

\section{References}

1. Tabarsi, E., Kozak, R., Cohen, D., Gaston, C.: A market assessment of the potential for OSB products in the North American office 
furniture and door manufacturing industries. For. Prod. J. 53(7-8), 19-27 (2003)

2. Madurwar, M., Ralegaonkar, R.V., Mandavgane, S.A.: Application of agro-waste for sustainable construction materials: a review. Constr. Build. Mater. 38, 872-878 (2013)

3. Buyuksari, U., Ayrilmis, N., Avci, E., Koc, E.: Evaluation of the physical, mechanical properties and formaldehyde emission of particleboard manufactured from waste stone pine (Pinus pinea L.) cones. Bioresour. Technol. 101, 255-259 (2009)

4. Çöpür, Y., Güler, C., Taşçıŏlu, C., Tozluoğlu, A.: Incorporation of hazelnut shell and husk in MDF production. Bioresour. Technol. 99, 7402-7406 (2008)

5. Pirayesh, H., Khazaeian, A.: Using almond (Prunus amygdalus L.) shell as a biowaste resource in wood based composite. Composites B 43, 1475-1479 (2012)

6. Batalla, L., Nuñez, A.J., Marcovich, N.E.: Particleboards from peanut shell flour. J. Appl. Polym. Sci. 97, 916-923 (2005)

7. Guler, C., Copur, Y., Tascioglu, C.: The manufacture of particleboards using mixture of peanut hull (Arachis hypogaea L.) and European black pine (Pinus nigra Arnold) wood chips. Bioresour. Technol. 99, 2893-2897 (2008)

8. Wechsler, A., Zaharia, M., Crosky, A., Jones, H., Ramírez, M., Ballerini, A., Nuñez, V., Sahajwalla, M.: Macadamia (Macadamia integrifolia) shell and castor (Rícinos communis) oil based sustainable particleboard: a comparison of its properties with conventional wood based particleboard. Mater. Des. 50, 117-123 (2013)

9. Bektas, I., Guler, C., Kalaycioğlu, H., Mengeloglu, F., Nacar, M.: The manufacture of particleboards using sunflower stalks (Helianthus annuus L.) and poplar wood (Populus alba L.). J. Compos. Mater. 39, 467-473 (2005)

10. Guntekin, E., Karakus, B.: Feasibility of using eggplant (Solanum melongena) stalks in the production of experimental particleboard. Ind. Crops Prod. 27, 354-358 (2008)

11. Quintana, G.C., Velásquez Jiménez, J.A., Betancourt, S., Gañán, P.F.: Binderless fiberboard from steam exploded banana bunch. Ind. Crops Prod. 29(1), 60-66 (2009)

12. Sampathrajan, A., Vijayaraghavan, N.C., Swaminathan, K.R.: Mechanical and thermal properties of particle boards made from farm residues. Bioresour. Technol. 40, 249-251 (1992)

13. Kadam, V., Chattopadhyay, K., Bharimalla, A., Venugopal, B.: Mechanical characterization of brown and green coconut husk. J. Nat. Fibers 11(4), 322-332 (2014)

14. Xu, R., Sugawara, Y., Widyorini, R., Han, G.P., Kawai, S.: Manufacture and properties of low-density binderless particleboard from kenaf core. Wood Sci. 50, 62-67 (2004)

15. Machado Cravo, J.C., de Lucca Sartori, D., Màrmol, G., de Carvalho Balieiro, J.C., de Oliveira Machado, G., Fiorelli, J.: Manufacture of particleboard based on cement bag and castor oil polyurethane resin. Constr. Build. Mater. 87, 8-15 (2015)

16. Hernández-Salas, J.M., Villa-Ramírez, M.S., Veloz-Rendó, N.J.S., Rivera-Hernández, K.N., González-César, R.A., PlascenciaEspinosa, M.A., et al.: Comparative hydrolysis and fermentation of sugarcane and agave bagasse. Bioresour. Technol. 100, 1238-1245 (2009)

17. Pandey, A., Soccol, C.R., Nigam, P., Soccol, V.T.: Biotechnological potential of agro-industrial residues. I: sugarcane bagasse. Bioresour. Technol. 74, 69-80 (2000)

18. Loh, Y.R., Debnath, S., Ekhlasur Rahman, M., Das, C.A.: Sugarcane bagasse-the future composite material: a literature review. Resour. Conserv. Recycl. 75, 14-22 (2013)

19. Vilay, V., Jaafar, M., Mat Taib, R., Todo, M.: Effect of fiber surface treatment and fiber loading on the properties of bagasse fiber-reinforced unsaturated polyester composites. Compos. Sci. Technol. 68, 631-638 (2008)

20. de Sousa, M.V., Monteiro, S., d'Almeida, J.R.M.: Evaluation of pre-treatment, size and molding pressure on flexural mechanical behavior of chopped bagasse-polyester composites. Polym. Test. 23, 253-258 (2004)

21. Carvajal, O., Valdés, J.L., Puig, J.: Bagasse particleboards for building purpose. Holz als Roh- und Werkstoff 54(1), 61-63 (1996)

22. Nonaka, S., Umemura, K., Kawai, S.: Characterization of bagasse binderless particleboard manufactured in high-temperature range. J. Wood Sci. 59, 50-56 (2013)

23. Fiorelli, J., de Lucca Sartori, D., Machado Cravo, J.C.: Savastano Jr., H., Rossignolo, J.A., do Nascimento, M.F., Rocco Lahr, F.A.: Sugarcane bagasse and castor oil polyurethane adhesive-based particulate composite. Mater. Res. 16(2), 439-446 (2013)

24. Zike, S., Kalnins, K.: Enhanced impact absorption properties of plywood. In: Civil Engineering'11, 3rd International Scientific Conference Proceedings, Jelgava, Latvia, 2011, pp. 125-130

25. Sfarra, S., López, F., Sarasini, F., Tirillò, J., Ferrante, L., Perilli, S., Ibarra-Castanedo, C., Paoletti, D., Lampani, L., Barbero, E., Sánchez-Sáez, S., Maldague, X.: Analysis of damage in hybrid composites subjected to ballistic impacts: an integrated nondestructive approach. In: Thakur, V.K., Thakur, M.K., Kessler, M.R. (eds) Handbook of Composites from Renewable Materials. Physico-chemical and Mechanical Characterization, vol. 3, pp. 175-210. Wiley-Scrivener (2017). ISBN 978-1-119-22366-5

26. Tang, Z., Hang, C., Suo, T., Wang, Y., Dai, L., Zhang, Y.: Numerical and experimental investigation on hail impact on composite panels. Int. J. Impact Eng. (2016). https://doi.org/10.1016/j.ijimpeng. 2016.05.016

27. Bendada, A., Sfarra, S., Genest, M., Paoletti, D., Rott, S., Talmy, E., Ibarra-Castanedo, C., Maldague, X.: How to reveal subsurface defects in Kevlar ${ }^{\circledR}$ composite materials after an impact loading using infrared vision and optical NDT techniques? Eng. Fract. Mech. 108, 195-208 (2013)

28. Meola, C., Carlomagno, G.M.: Infrared thermography to evaluate impact damage in glass/epoxy with manufacturing defects. Int. J. Impact Eng. 67, 1-11 (2014)

29. Shi, W., Wu, Y., Wu, L.: Quantitative analysis of the projectile impact on rock using infrared thermography. Int. J. Impact Eng. 34, 990-1002 (2007)

30. Prentice, H.J., Proud, W.G., Walley, S.M., Field, J.E.: Optical techniques for the investigation of the ballistic impact of thin plates. Int. J. Impact Eng. 38, 849-863 (2011)

31. Sfarra, S., Ibarra-Castanedo, C., Santulli, C., Sarasini, F., Ambrosini, D., Paoletti, D., Maldague, X.: Eco-friendly laminates: from the indentation to non-destructive evaluation by optical and infrared monitoring techniques. Strain 49, 175-189 (2013)

32. Sfarra, S., Ibarra-Castanedo, C., Santulli, C., Paoletti, A., Paoletti, D., Sarasini, F., Bendada, A., Maldague, X.: Falling weight impacted glass and basalt fibre woven composites inspected using non-destructive techniques. Composites B 45, 601-608 (2013)

33. Sfarra, S., Ibarra-Castanedo, C., Santulli, C., Paoletti, D., Maldague, X.: Monitoring of jute/hemp fiber hybrid laminates by nondestructive testing techniques. Sci. Eng. Compos. Mater. 23(3), 283-300 (2016)

34. Sfarra, S., Theodorakeas, P., Černecky, J., Pivarčiová, E., Perilli, S., Koui, M.: Inspecting marquetries at different wavelengths: the preliminary numerical approach as aid for a wide-range of nondestructive tests. J. Nondestruct. Eval. 36(6), 1-20 (2017)

35. Blaber, J., Adair, B., Antoniou, A.: Ncorr: open-source digital image correlation Matlab software. Exp. Mech. 55(6), 1105-1122 (2015a)

36. Blaber, J., Adair, B.S., Antoniou, A.: A methodology for high resolution digital image correlation in high temperature experiments. Rev. Sci. Instrum. 86, 035111-1-035111-6 (2015b)

37. Zhang, H., Hassler, U., Genest, M., Fernandes, H., Robitaille, F., Ibarra-Castanedo, C., Joncas, S., Maldague, X.: Comparative study on submillimeter flaws in stitched T-joint carbon fiber reinforced polymer by infrared thermography, microcomputed tomography, 
ultrasonic c-scan and microscopic inspection. Opt. Eng. 54(10), 104109 (2015)

38. Fernandes, H., Zhang, H., Ibarra-Castanedo, C., Maldague, X.: Fiber orientation assessment on randomly-oriented strand composites by means of infrared thermography. Compos. Sci. Technol. 121, 25-33 (2015)

39. Sham, F.C., Xu, W.T., Lo, T.: Application of flash thermography for crack identification in concrete materials. Insight 52(9), 494-497 (2010)

40. Arndt, R.W.: Square pulse thermography in frequency domain as adaptation of pulsed phase thermography for qualitative and quantitative applications in cultural heritage and civil engineering. Infrared Phys. Technol. 53(4), 246-253 (2010)

41. Renshaw, J., Chen, J.C., Holland, S.D., Thompson, R.B.: The sources of heat generation in vibrothermography. NDT\&E Int. 44(8), 736-739 (2011)

42. Oswald-Tranta, B., Sorger, S.: Scanning pulse phase thermography with line heating. QIRT J. 9(2), 103-122 (2012)

43. Ibarra-Castanedo, C., Tarpani, J.R., Maldague, X.P.V.: Nondestructive testing with thermography. Eur. J. Phys. 34, S91-S109 (2013)

44. Rajic, N.: Principal component thermography for flaw contrast enhancement and flaw depth characterization in composite structures. Compos. Struct. 58(4), 521-528 (2002)

45. Zhang, H., Yu, L., Hassler, U., Fernandes, H., Genest, M., Robitaille, F., Joncas, S., Holub, W., Sheng, Y., Maldague, X.: An experimental and analytical study of micro-laser line thermography on micro-sized flaws in stitched carbon fiber reinforced polymer composites. Compos. Sci. Technol. 126, 17-26 (2016)

46. Zhang, H., Fernandes, H., Dizeu, F., Hassler, U., Fleuret, J., Genest, M., Ibarra-Castanedo, C., Robitaille, F., Joncas, S., Maldague, $\mathrm{X}$.: Pulsed micro-laser line thermography on submillimeter porosity in carbon fiber reinforced polymer composites: experimental and numerical analyses for the capability of detection. Appl. Opt. 55(34), D1-D10 (2016)

47. Pawar, S.S., Vavilov, V.P.: Applying the heat conduction-based 3D normalization and thermal tomography to pulsed infrared thermography for defect characterization in composite materials. Int. J. Heat Mass Transf. 94, 56-65 (2016)

48. American Society for Testing and Materials (ASTM): D 1037: Standard Test Method for Evaluating Properties of Wood-Base Fiber and Particle Panel Materials. ASTM, Philadelphia (1996)

49. Fiorelli, J., Curtolo, D.D., Barrero, N.G., Savastano Jr., H., Pallone, E.M.J.A., Johnson, R.: Particulate composite based on coconut fiber and castor oil polyurethane adhesive: an ecoefficient product. Ind. Crops Prod. 40, 69-75 (2012)

50. Associação Brasileira de Normas Técnicas (ABNT): NBR 14810: Chip Panel Sheets_-Part 3: Testing Methods, Terminology. ABNT, Rio de Janeiro (2006)

51. Lopresto, V., Caprino, G., Leone, C., Langella, A.: A damage index of indentation sensitivity in low velocity impact conditions. Polym. Compos. 36, 987-991 (2015)

52. Caprino, G., Lopresto, V.: The significance of indentation in the inspection of carbon fibre-reinforced plastic panels damaged by low-velocity impact. Compos. Sci. Technol. 60(7), 1003-1012 (2000)

53. Belingardi, G., Vadori, R.: Low velocity impact tests of laminate glass-fiber-epoxy matrix composite material plates. Int. J. Impact Eng. 27(2), 213-229 (2002)

54. Wos, P., Michalcki, J.: Effect of initial cylinder liner honing surface roughness on aircraft piston engine performances. Tribol. Lett. 41, 555-567 (2011)

55. Schönauer, W., Adolph, T.: How we solve PDEs. J. Comput. Appl. Math. 131(1-2), 473-492 (2001)

56. Introduction to Comsol Multiphysics®. http://cdn.comsol.com/ documentation/5.0.1.276/IntroductionToCOMSOLMultiphysics. pdf. Accessed 1 May 2016
57. Constitutive Equation. http://web.mit.edu/16.20/homepage/3_ Constitutive/Constitutive_files/module_3_with_solutions.pdf. Accessed 26 May 2016

58. Javier, J., Majano-Majano, A., Fernandez-Cabo, J.: On the identifiability of stiffness components of clear wood from a 3D off-axes prismatic specimen: angle orientation and friction effects. Eur. J. Wood Wood Prod. 74(3), 285-290 (2016)

59. Rasul, M.G., Rudolph, V., Carsky, J.M.: Physical properties of bagasse. Fuel 78(8), 905-910 (1999)

60. Han, Y.W., Catalano, E.A., Ciegler, A.: Chemical and physical properties of sugarcane bagasse irradiated with gamma rays. J. Agric. Food Chem. 31(1), 34-38 (1983)

61. Fiorelli, J., Gomide, C.A.: Lahr, F.A.R., do Nascimento, M.F., de Lucca Sartori, D., Mejia Ballesteros, J.E., Bonila Bueno, S., Belini, U.L.: Physico-chemical and anatomical characterization of residual lignocellulosic fibers. Cellulose 21(5), 3269-3277 (2014)

62. Öchsner, A.: Elasto-plasticity of Frame Structure Elements Modeling and Simulation of Rods and Beams. Springer, Berlin (2014). ISBN 978-3-662-44224-1

63. Maldague, X.P.: Theory and Practice of Infrared Technology for Nondestructive Testing. Wiley Interscience, New York (2001)

64. Zhang, H., Fernandes, H., Hassler, U., Ibarra-Castanedo, C., Genest, M., Robitaille, F., Joncas, S., Maldague, X.: Comparative study of microlaser excitation thermography and microultrasonic excitation thermography on submillimeter porosity in carbon fiber reinforced polymer composites. Opt. Eng. 56(4), 041304 (2016)

65. Ibarra-Castanedo, C., Genest, M., Guibert, S., Piau, J.-M., Maldague, X.P.V., Bendada, A.: Inspection of aerospace materials by pulsed thermography, lock-in thermography, and vibrothermography: a comparative study. In: Knettel, K.M., Vavilov, V.P., Miles, J.J. (eds) Proceedings of SPIE, Thermosense XXIX, vol. 6541, 2007

66. Zhang, H., Sfarra, S., Saluja, K., Peeters, J., Fleuret, J., Duan, Y., Fernandes, H., Avdelidis, N., Ibarra-Castanedo, C., Maldague, X.: Non-destructive investigation of paintings on canvas by continuous wave terahertz imaging and flash thermography. J. Nondestruct. Eval. 36(2), 1-12 (2017)

67. Gruss, C., Balageas, D.: Theoretical and experimental applications of the flying spot camera. In: EETI (ed) Proceedings of QIRT 1992-The International Conference on Quantitative Infrared Thermography—Eurotherm Series 27, 1992

68. Deonna Woolard, F., Elliott Cramer, K.: Line scan versus flash thermography: comparative study on reinforced carbon-carbon. In: Raymond Peacock, G., Burleigh, D.D., Miles, J.J. (eds) Proceedings of SPIE, Thermosense XXVII, vol. 5782, pp. 315-323, 2005

69. Ibarra-Castanedo, C., Servais, P., Ziadi, A., Klein, M., Maldague, X.: RITA — robotized inspection by thermography and advanced processing for the inspection of aeronautical components. In: Batsale, J.-C., Balageas, D., Battaglia, J.-L., et al. (eds) Proceedings of QIRT 2014-The 12th International Conference on Quantitative Infrared Thermography, vol. XXII (2014). http://www.ndt.net/article/qirt2014/papers/QIRT-2014-164.pdf

70. Aindow, J., Markham, M., Puttick, K., Rider, J., Rudman, M.: Fibre orientation detection in injection-moulded carbon fibre reinforced components by thermography and ultrasonics. NDT\&E Int. 19(1), 24-29 (1986)

71. Ball, R.J., Almond, D.P.: Detection and measurements of impact damage in thick carbon fibre reinforced laminates by transient thermography. NDT\&E Int. 31, 165-173 (1998)

72. Avdelidis, N.P., Almond, D.P., Dobbinson, A., Hawtin, B.C.: Pulsed thermography: philosophy, qualitative and quantitative analysis on certain aircraft applications. Insight 48(5), 286-289 (2006) 
73. Zhang, H., Sfarra, S., Sarasini, F., Ibarra-Castanedo, C., Perilli, S., Fernandes, H., Duan, Y., Peeters, J., Avdelidis, N.P., Maldague, M.: Optical and mechanical excitation thermography for impact response in basalt-carbon hybrid fiber-reinforced composite laminates. IEEE Trans. Ind. Inform. (2017). https://doi.org/10.1109/ TIII.2017.2744179

74. Balageas, D., Maldague, X., Burleigh, D., Vavilov, V.P., OswaldTranta, B., Roche, J.-M., Pradere, C., Carlomagno, G.M.: Thermal (IR) and other NDT techniques for improved material inspection. J. Nondestruct. Eval. 35, 1-17 (2016)
75. Fernandes, H., Ibarra-Castanedo, C., Zhang, H., Maldague, X.P.V.: Thermographic non-destructive evaluation of carbon fiberreinforced polymer plates after tensile testing. J. Nondestruct. Eval. 34, 35-45 (2015)

76. Vavilov, V.P.: Modeling and characterizing impact damage in carbon fiber composites by thermal/infrared non-destructive testing. Composites B 61, 1-10 (2014)

77. Ahi, K.: Mathematical modeling of THz point spread function and simulation of $\mathrm{THz}$ imaging systems. IEEE Trans. Terahertz Sci. Technol. 7(6), 747-754 (2017). https://doi.org/10.1109/TTHZ. 2017.2750690 